\title{
Application of a new carboxylate-functionalized sugarcane bagasse for adsorptive removal of crystal violet from aqueous solution: Kinetic, equilibrium and thermodynamic studies
}

\author{
Bruno Christiano Silva Ferreira ${ }^{a}$, Filipe Simões Teodorob ${ }^{\mathrm{b}}$, Aparecida Barbosa Mageste $^{\mathrm{b}}$, \\ Laurent Frédéric Gil ${ }^{\mathrm{b}}$, Rossimiriam Pereira de Freitas ${ }^{\mathrm{a}, * *}$, \\ Leandro Vinícius Alves Gurgel ${ }^{\mathrm{b}, *}$ \\ a Departamento de Química, Instituto de Ciências Exatas (ICEx), Universidade Federal de Minas Gerais, Avenida Antônio Carlos, 6627, \\ 31270-901 Belo Horizonte, Minas Gerais, Brazil

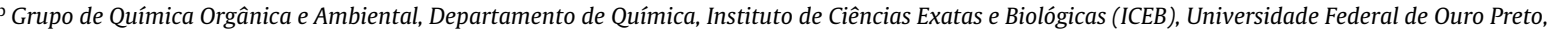 \\ Campus Universitário Morro do Cruzeiro, s/n`, Bauxita, 35400-000 Ouro Preto, Minas Gerais, Brazil
}

\section{A R T I C L E I N F O}

Article history:

Received 7 August 2014

Received in revised form

12 September 2014

Accepted 12 October 2014

Available online 4 November 2014

\section{Keywords:}

Sugarcane bagasse

Meldrum's acid

Solvent-free

Adsorption

Crystal violet

Thermodynamic studies

\begin{abstract}
A B S T R A C T
A new carboxylate-functionalized sugarcane bagasse (SMA) was prepared via a solvent-free procedure involving esterification of sugarcane bagasse with Meldrum's acid. The optimized conditions provided SMA with a percent weight gain of $86.0 \%$ and $4.69 \pm 0.20 \mathrm{mmol} / \mathrm{g}$ of carboxylic acid groups. SMA was characterized by FTIR, TGA, elemental analysis and SEM. Kinetic experiments showed that the amount of crystal violet adsorbed increased with increasing temperature and equilibrium was reached at $12 \mathrm{~h}$. Adsorption kinetics followed a pseudo-second-order model. The Arrhenius and Eyring models were used to obtain the activation energy and changes in free energy, enthalpy, and entropy of activation for the adsorption process. The calculated activation energy $(14.14 \mathrm{~kJ} / \mathrm{mol})$ suggested physical adsorption of CV onto SMA. The equilibrium data were well fitted to the Langmuir and Sips isotherms. Maximum adsorption capacity was $692.1 \mathrm{mg} / \mathrm{g}$ at $45^{\circ} \mathrm{C}$. Thermodynamic parameters such as changes in free energy, enthalpy and entropy were also determined.
\end{abstract}

(C) 2014 Elsevier B.V. All rights reserved.

\section{Introduction}

Synthetic dyes are widely used in the paper, textile, food and pharmaceutical industries (Mittal et al., 2010). It is estimated that there are more than 100,000 types of commercially available dyes and an annual worldwide production of $700,000-1,000,000$ tons has been reported in the literature (Gupta and Suhas, 2009; Pang and Abdullah, 2013). It is also estimated that 280,000 tons of dyes are discharged as industrial effluents every year worldwide (Ali, 2010; Pang and Abdullah, 2013). Water consumption by the textile industry is $100 \mathrm{~m}^{3}$ /ton of product, on average. Furthermore, the global demand for dyes and pigments is expected to grow at an

\footnotetext{
* Corresponding author. Tel.: +55 313559 1707; fax: +55 3135591707 .

** Corresponding author. Tel.: +55 313409 5732; fax +55 3134095711 .

E-mail addresses: rossipdf@yahoo.com.br (R.P.de Freitas), legurgel@iceb.ufop.br (L.V.A. Gurgel).
}

average of $3.5 \%$ per year, from 1.9 million tons in 2008 to 2.3 million in 2013 (Pang and Abdullah, 2013).

Crystal violet (CV) is also known as basic violet 3, gentian violet and methyl violet 10B. It is used for various purposes such as a biological stain, a dermatological agent, a veterinary medicine, and an additive to poultry feed to inhibit propagation of mold, intestinal parasites and fungus (Saquib and Muneer, 2003). It is also extensively used in dying textiles and coloring in paper. CV is a mutagen and mitotic poison (Sahoo et al., 2005) and can form a proteindye complex and hence acts as an enhancer for bloody fingerprints (Liu et al., 2013). CV is carcinogenic and has been classified as a recalcitrant molecule; since it is poorly metabolized by microorganisms, it can therefore persist in a variety of environments (Thompson Jr et al., 1999). It is responsible for causing moderate eye irritation, producing painful sensitization to light (Ahmad, 2009). It can also cause permanent injury to the cornea and conjunctiva. It is highly toxic to mammalian cells; and, if absorbed in harmful amounts by the skin, can cause skin and digestive tract irritations. In extreme cases, it may also lead to respiratory and kidney failures 
(Ahmad, 2009; Kaur et al., 2013; Mittal et al., 2010; Saeed et al., 2010). Therefore, it is crucial to propose new environmentally friendly processes with low cost and high efficiency to remove CV from industrial effluents and water bodies.

A number of processes to remove dyes, comprising aerobic and anaerobic microbial degradation, coagulation, membrane separation, electrochemical treatment, filtration, flocculation, softening, hydrogen peroxide catalysis, and reverse osmosis have been studied in recent years (Brosillon et al., 2008; Gupta et al., 2012; Gupta and Suhas, 2009; Kaur et al., 2013; Liang et al., 2014; Matouq et al., 2014; Saba et al., 2013). Nevertheless, these treatment processes have drawbacks and limitations related to high cost, generation of secondary pollutants and reduced removal efficiency (Kaur et al., 2013; Wang, 2012). Adsorption, however, has been demonstrated to be an effective and attractive process to treat effluents containing dyes. Adsorption has clear advantages because of its ease of operation, insensitivity to toxic pollutants, ability to treat concentrated dye wastes, the possibility of reusing the spent adsorbent via desorption (Kaur et al., 2013), recycling water from the process, and recovering the dyes. These may all diminish the overall cost of the process. In recent years, various adsorbents based on agricultural wastes and by-products as sugarcane bagasse, jute fiber, rice husk, barley husk, citrus waste or sunflower seed hull have been reported and applied for removal of dye matters from aqueous solutions. A recent review provides an extensive comparison between different types of biosorbents from lignocellulosic wastes, their kinetic and thermodynamic studies, as well as their applications for dyes or organic pollutants removal (Abdolali et al., 2014).

Lignocellulosic materials are one of the most common adsorbents since they are raw materials of low cost, available in large amounts as by-products from cellulosic pulp and paper manufacturing, and are found in first and second-generation biofuel production. The global sugarcane agro-industry processed more than $1685 \times 10^{6}$ tons in 2010 . This amount of sugarcane bagasse generated $23.6 \times 10^{6}$ tons of bagasse on a dry basis (Pippo and Luengo, 2013). Such a large amount of sugarcane bagasse available in the world makes it an attractive option for technological applications since it can be used to obtain numerous industrial products, such as biofuels (second generation ethanol), bioelectricity, biodegradable polymers and various other commodities (Shaikh et al., 2009). Furthermore, sugarcane bagasse has a large content of hydroxyl groups from cellulose, hemicelluloses, and lignin that can be used as reactive sites to produce new adsorbent materials with specific properties (Karnitz et al., 2009).

Various kinds of surface modifications of lignocellulosic materials have been proposed (Abdolali et al., 2014; Gupta and Suhas, 2009); however, the use of organic solvents such as pyridine, triethylamine, $N, N^{\prime}$-dimethylacetamide (DMA), N, N'dimethylformamide (DMF), and dimethyl sulfoxide (DMSO), among others, may compromise the viability of the chemical modification process due to the high cost of the organic solvent or its toxicity. Thus, the study of surface modifications of lignocellulosic materials without the use of organic solvents can improve the economic feasibility of the process, and also produce new green-based adsorbent materials that are environmentally amenable to adsorbing various pollutants. Several research groups around the world have been working on solvent-free mechanochemistry routes or on cleaner routes using ultrasound and microwave radiation, but in these routes, a relatively low percentage of introduced carboxylic acid functions have been reported (Kalidhasan et al., 2012; Ma et al., 2012; Melo et al., 2011; Soliman et al., 2011; Vieira et al., 2010; Zhang et al., 2010).

Thus, this study aimed to prepare a new adsorbent material from sugarcane bagasse via a solvent-free procedure using Meldrum's acid as an esterification agent. Meldrum's acid is a commercial, non-toxic, stable and easily prepared reagent commonly used in organic synthesis (Bigi et al., 2001; Ehlert et al., 2011; Leibfarth et al., 2010; Ryu and Scott, 2003). Meldrum's acid has already been used in material chemistry to introduce carboxylic functions in carbon fibers (Ehlert et al., 2011). This study also aimed to use the modified material to remove crystal violet (CV) from single aqueous solution and to assess the adsorption kinetics, the influence of $\mathrm{pH}$ on adsorption and the effect of the initial concentration of CV to determine the parameters affecting the adsorption system. The transition state and thermodynamic data were used to understand and suggest the adsorption mechanism.

\section{Experimental}

\subsection{Materials}

Crystal violet dye (CV, $\mathrm{C}_{25} \mathrm{H}_{30} \mathrm{~N}_{3} \mathrm{Cl}, \quad \lambda \max =584 \mathrm{~nm}$, $\mathrm{MM}=407.98 \mathrm{~g} / \mathrm{mol}$ ) was purchased from Vetec (Brazil). 2,2Dimethyl-1,3-dioxane-4,6-dione (98\%) (Meldrum's acid) was purchased from Sigma-Aldrich (Brazil). $\mathrm{NaHCO}_{3}, \mathrm{NaOH}, \mathrm{HCl}$ $(37 \%, w / w), 95 \%$ ethanol and acetone were purchased from Synth (Brazil).

\subsection{Sugarcane bagasse preparation}

Sugarcane bagasse (SB) was provided by a local sugar company, Ouro Preto, Minas Gerais, Brazil. Shortly after being collected, raw bagasse stalks were cut to reduce their length and then dried in an oven at $90^{\circ} \mathrm{C}$ for $24 \mathrm{~h}$. After that, they were pulverized in a vibratory disc mill equipped with tungsten carbide. The powder was sifted in a four-sieve system composed of screens of 60 $(0.251 \mathrm{~mm}), 100(0.149 \mathrm{~mm})$ and $200(0.075 \mathrm{~mm})$ mesh. The fraction retained between 100 and 200 mesh was collected, transferred to a $5 \mathrm{~L}$ Becker, suspended in distilled water at $70^{\circ} \mathrm{C}$ and magnetically stirred for $1 \mathrm{~h}$ with the aim of removing residual sugars. Then, the suspension was recovered by vacuum filtration using a sintered glass Büchner funnel (porosity 3), washed with 95\% EtOH and dried at $90^{\circ} \mathrm{C}$ in an oven for $2 \mathrm{~h}$. Finally, it was washed in a Soxhlet apparatus with hexane:ethanol $(1: 1, \mathrm{v} / \mathrm{v})$ for $4 \mathrm{~h}$ to remove the extractives, dried at $90^{\circ} \mathrm{C}$ in an oven to remove the organic solvents, and stored in a desiccator prior to use.

\subsection{Preparation of sugarcane bagasse modified with Meldrum's acid (SMA)}

The study of the chemical modification of sugarcane bagasse with Meldrum's acid to produce SMA was divided into two parts: the influence of reaction time and the amount of Meldrum's on the yield of SMA.

\subsubsection{Modification of sugarcane bagasse as a function of reaction time}

Sugarcane bagasse (SB) ( $0.5 \mathrm{~g})$ and Meldrum's acid ( $0.5 \mathrm{~g})$ were added to a round-bottom flask equipped with a reflux condenser and heated at $110^{\circ} \mathrm{C}$ for $1 \mathrm{~h}$ in an oil bath under constant magnetic stirring. At the end of the reaction, the suspension mixture was transferred to a sintered glass Büchner funnel (porosity 3), filtered, and washed with an excess of distilled water to remove the non-reacted Meldrum's acid and then with acetone. Sugarcane bagasse modified with Meldrum's acid (SMA) was dried in an oven at $90^{\circ} \mathrm{C}$ for $1 \mathrm{~h}$ and stored in a desiccator. After cooling, the percent weight gain was calculated and the number of carboxylic acid groups ( $\left.n_{\mathrm{COOH}}\right)$ was determined (Gurgel et al., 2008). The same reaction procedure was performed with further reaction times of 2,4 , 6,12 and $24 \mathrm{~h}$. 


\subsubsection{Modification of sugarcane bagasse as a function of the amount of Meldrum's acid}

Sugarcane bagasse (SB) $(0.5 \mathrm{~g})$ and different amounts of Meldrum's acid $(0.5,1.0,1.5,2.0$ and $3.0 \mathrm{~g})$ were added to a round-bottom flask equipped with a reflux condenser and heated at $110^{\circ} \mathrm{C}$ in an oil bath under constant magnetic stirring for $4 \mathrm{~h}$. The reaction procedures and subsequent characterization were the same as described in Section 2.3.1.

\subsection{Characterization of SMA}

\subsubsection{Percent weight gain ( $p w g)$} (1).

The percent weight gain ( $p w g$ ) was calculated according to Eq.

$$
p w g / \%=\left(\frac{w_{\mathrm{SMA}}-w_{\mathrm{SB}}}{w_{\mathrm{SB}}}\right) \times 100
$$

where $w_{\text {SMA }}(\mathrm{g})$ is the weight of modified sugarcane bagasse with Meldrum's acid bagasse and $w_{\mathrm{SB}}(\mathrm{g})$ is the weight of sugarcane bagasse.

\subsubsection{Number of carboxylic acid groups $\left(n_{\mathrm{COOH}}\right)$}

The number of carboxylic acid groups $\left(n_{\mathrm{COOH}}\right)$ in the synthesized SMA using the optimized reaction conditions (sugarcane bagasse:Meldrum's acid ratio of 1:6 and reaction time of $4 \mathrm{~h}$ ) was determined by acid-base back titration. Three samples of $0.1000 \mathrm{~g}$ of SMA were weighed and transferred to $250 \mathrm{~mL}$ Erlenmeyer flasks. To each flask, $100.0 \mathrm{~mL}$ of standardized $\mathrm{NaOH}$ solution $(10 \mathrm{mmol} / \mathrm{L})$ was added. The flasks were mechanically stirred at $25^{\circ} \mathrm{C}$ for $30 \mathrm{~min}$ and then the suspensions were separated by single filtration. Three aliquots of $25.0 \mathrm{~mL}$ from each Erlenmeyer flask were titrated with standardized $\mathrm{HCl}$ solution $(10 \mathrm{mmol} / \mathrm{L})$ until phenolphthalein endpoint. The number of carboxylic acid groups per gram of adsorbent material (SMA) was calculated using Eq. (2) as follows.

$n_{\mathrm{COOH}} /(\mathrm{mmol} / \mathrm{g})=\left(\frac{C_{\mathrm{NaOH}} V_{\mathrm{NaOH}}-C_{\mathrm{HCl}} V_{\mathrm{HCl}} f}{w_{\mathrm{SMA}}}\right) \times 100$

where $C_{\mathrm{NaOH}}$ is the concentration of the standardized $\mathrm{NaOH}$ solution $(\mathrm{mmol} / \mathrm{L}), C_{\mathrm{HCl}}$ is the concentration of the standardized $\mathrm{HCl}$ solution $(\mathrm{mmol} / \mathrm{L}), V_{\mathrm{NaOH}}$ is the volume of the standardized $\mathrm{NaOH}$ solution (L), $V_{\mathrm{HCl}}$ is the volume of standardized $\mathrm{HCl}$ solution expended titrating the excess unreacted $\mathrm{NaOH}, w_{\mathrm{SMA}}$ is the weight of the adsorbent material $(0.1000 \mathrm{~g})$, and $f$ is the conversion factor taking into account the aliquot $(25.0 \mathrm{~mL})$ used in each titration $(f=4)$.

To determine the number of carboxylate groups $\left(n_{\mathrm{COO}-}\right)$ released after treating SMA with saturated $\mathrm{NaHCO}_{3}$ solution a similar procedure to the one described above was used; however, the solid was put in contact with a standardized $\mathrm{HCl}$ solution instead of $\mathrm{NaOH}$, and titrated with a standardized $\mathrm{NaOH}$ solution.

\subsubsection{FTIR analysis}

The SB and SMA (in its acidic and basic forms) were analyzed by FTIR spectroscopy. Samples were prepared for analyses by mixing $1 \mathrm{mg}$ of each material previously dried in an oven at $90^{\circ} \mathrm{C}$ for $1 \mathrm{~h}$ with $100 \mathrm{mg}$ of spectroscopy grade $\mathrm{KBr}$. The FTIR spectra were recorded on an IR SPECTRUM ASCII PEDS 1.60 spectrometer with the detector at a resolution of $4 \mathrm{~cm}^{-1}$ from 400 to $4000 \mathrm{~cm}^{-1}$ and 32 scans per sample.

\subsubsection{Elemental analysis}

The SB and SMA adsorbent (in acidic form) were first washed with acetone and dried in an oven at $90^{\circ} \mathrm{C}$ for $1 \mathrm{~h}$ before analysis. The elemental analyses were accomplished using a Perkin Elmer Series II CHN model 2400 analyzer.

\subsubsection{Thermogravimetric analysis (TGA)}

Thermogravimetric analysis was carried out in a Shimadzu DTG$60 \mathrm{H}$ simultaneous TG-DTA. Powder samples of $2.5 \mathrm{mg}$ of SB and SMA (in its acidic and basic forms) were placed on aluminum pans. TGA experiments were performed under nitrogen atmosphere at a flow rate of $100 \mathrm{~mL} / \mathrm{min}$. Samples were heated from 25 to $700^{\circ} \mathrm{C}$ at a linear heating rate of $10^{\circ} \mathrm{C} / \mathrm{min}$.

\subsubsection{Determination of the point of zero charge $\left(\mathrm{pH}_{\mathrm{PZC}}\right)$}

The $\mathrm{pH}$ of the point of zero charge $\left(\mathrm{pH}_{\mathrm{PZC}}\right)$ of SMA was determined using the mass titration method according to (Noh and Schwarz, 1990). $\mathrm{NaNO}_{3}(0.01 \mathrm{~mol} / \mathrm{L})$ solutions with $\mathrm{pH}$ values of 3 , 6 and 11 were prepared using $0.1 \mathrm{~mol} / \mathrm{L} \mathrm{HNO}_{3}$ and $0.1 \mathrm{~mol} / \mathrm{L} \mathrm{NaOH}$ solutions. From each solution at $\mathrm{pH} \mathrm{3,6}$ and 11, five aliquots of $20.0 \mathrm{~mL}$ were taken and transferred to $100 \mathrm{~mL}$ Erlenmeyer flasks. Then, different amounts of SMA were added to the Erlenmeyer flasks to give suspensions of $0.5,1,5,10$ and $50 \%(\mathrm{w} / \mathrm{v})$. The equilibrium $\mathrm{pH}$ was measured using a $\mathrm{pH}$ meter (Hanna Instruments model HI 223) after $24 \mathrm{~h}$ of shaking at $150 \mathrm{rpm}$ at $26^{\circ} \mathrm{C}$.

\subsubsection{Scanning electron microscopy (SEM)}

The morphologies of the SB and the SMA adsorbent before and after adsorption of CV were examined with a Vega3 SB (Tescan/Oxford Instruments) SEM, using a filament voltage of $20 \mathrm{keV}$. The samples of SMA containing adsorbed CV were dried in an oven at $70^{\circ} \mathrm{C}$ for $2 \mathrm{~h}$. Dry powder samples were dispersed on a graphite ribbon fixed on aluminum sample holders. The powders were sputter-coated with gold in a modular high-vacuum coating system Q150R ES (Quorum Technologies).

\subsection{Adsorption experiments}

The SMA adsorbent material (in basic form) was used for CV adsorption in aqueous solutions in batch adsorption mode. The adsorption experiments were divided into adsorption as a function of adsorbent dosage, time (kinetics), $\mathrm{pH}$ and initial concentration of CV. The adsorption data were modeled by three kinetic and isotherm models. The adsorption kinetic constants obtained at different temperatures were used to assess parameters concerning the transition state of the adsorption process ( $\Delta_{\text {ads }} G^{\ddagger}, \Delta_{\text {ads }} H^{\ddagger}$ and $\Delta_{\text {ads }} S^{\ddagger}$ ), while the adsorption equilibrium constants, also obtained at different temperatures, were used to determine the thermodynamic parameters of adsorption $\left(\Delta_{\text {ads }} G^{\circ}, \Delta_{\text {ads }} H^{\circ}\right.$ and $\left.\Delta_{\text {ads }} S^{\circ}\right)$.

\subsubsection{Adsorption of CV onto SMA as a function of adsorbent dosage}

The effect of adsorbent dosage on CV removal was evaluated. Samples of 10.0, 20.0, 30.0, 40.0 and $50.0 \mathrm{mg}$ of SMA were weighed and added to $250 \mathrm{~mL}$ Erlenmeyer flasks containing $100.0 \mathrm{~mL}$ of CV solution of a known concentration $(125 \mathrm{mg} / \mathrm{L})$ at $\mathrm{pH}$ 7. The Erlenmeyer flasks were mechanically stirred at $150 \mathrm{rpm}$ in a shaker incubator (Tecnal, model TE-424, SP, Brazil) for $12 \mathrm{~h}$. At the end of each experiment, the suspension was subjected to centrifugation (Excelsa ${ }^{\circledR}$ II centrifuge, model $206 \mathrm{BL}$ ) at $3600 \mathrm{rpm}$ for $10 \mathrm{~min}$ to separate the solid and liquid phases. The concentration of CV in the supernatant phase was measured on a UV-Vis spectrophotometer (Biospectro model SP-220) at $584 \mathrm{~nm}$. Standard aqueous solutions of CV were prepared to build a calibration curve from which the concentration of $\mathrm{CV}$ was calculated. The $\mathrm{CV}$ removal percentage was calculated using Eq. (3).

$R / \%=\left(\frac{C_{o}-C_{t}}{C_{o}}\right) \times 100$

where $C_{o}$ and $C_{t}(\mathrm{mg} / \mathrm{L})$ are the initial and equilibrium concentrations in the $\mathrm{CV}$ solution. 


\subsubsection{Adsorption of CV onto SMA as a function of contact time} (kinetics)

Samples of $20.0 \mathrm{mg}$ of SMA were weighed and added to $250 \mathrm{~mL}$ Erlenmeyer flasks containing $100.0 \mathrm{~mL}$ of CV solution of a known concentration $(180 \mathrm{mg} / \mathrm{L})(\mathrm{pH} 7.0)$ pre-thermostated at 25,35 , 45 and $55^{\circ} \mathrm{C}$ in a thermostatic water-bath. Then, the Erlenmeyer flasks were transferred to a pre-thermostated shaker incubator and mechanically stirred at $150 \mathrm{rpm}$ for different time intervals depending on the temperature. After the adsorbent was in contact with the $\mathrm{CV}$ solution the $\mathrm{pH}$ of each suspension was measured using a $\mathrm{pH}$ meter but no significant changes in $\mathrm{pH}$ were noticed. After shaking, the solid and liquid phases were separated by centrifugation and the concentration of $\mathrm{CV}$ in the supernatant phase was measured as described in Section 2.5.1. The amount of CV adsorbed onto the SMA in each period of time was calculated using Eq. (4).

$q_{t} /(\mathrm{mg} / \mathrm{g})=\frac{\left(C_{i, \mathrm{CV}}-C_{t, \mathrm{CV}}\right) V_{\mathrm{CV}}}{w_{\mathrm{SMA}}}$

where $q_{t}(\mathrm{mg} / \mathrm{g})$ is the amount of CV adsorbed per weight of SMA at a time $t, V_{\mathrm{CV}}(\mathrm{L})$ is the volume of $\mathrm{CV}$ solution, $C_{i, \mathrm{CV}}(\mathrm{mg} / \mathrm{L})$ is the initial concentration of the $\mathrm{CV}$ solution, $C_{t, \mathrm{CV}}(\mathrm{mg} / \mathrm{L})$ is the concentration of CV solution at a time $t$ and $w_{\mathrm{SMA}}(\mathrm{g})$ is the weight of the SMA adsorbent material.

\subsubsection{Adsorption of CV onto SMA as a function of $p H$}

To evaluate the effect of $\mathrm{pH}$ on the adsorption of $\mathrm{CV}$ onto SMA, $20.0 \mathrm{mg}$ samples of SMA were weighed and added to $250 \mathrm{~mL}$ Erlenmeyer flasks containing $100.0 \mathrm{~mL}$ of $\mathrm{CV}$ solution of a known concentration $(200 \mathrm{mg} / \mathrm{L})$. The $\mathrm{pH}$ of the $\mathrm{CV}$ solutions had been adjusted previously to values between 3 and 9 by adding a few drops of aqueous $\mathrm{HCl}$ and $\mathrm{NaOH}$ solutions $(0.01-0.1 \mathrm{~mol} / \mathrm{L}$ ) prior to contact with the adsorbent. The $\mathrm{pH}$ of each suspension was measured using a $\mathrm{pH}$ meter during the experiment and no significant changes in $\mathrm{pH}$ were noticed. The Erlenmeyer flasks were transferred to a pre-thermostated shaker incubator at $25^{\circ} \mathrm{C}$ and mechanically stirred at $150 \mathrm{rpm}$ until equilibrium was reached $(12 \mathrm{~h})$. After shaking, the solid and liquid phases were separated by centrifugation, and the concentration of $\mathrm{CV}$ in the supernatant phase was measured as described in Section 2.5.1. Standard aqueous solutions of $\mathrm{CV}$ at each $\mathrm{pH}$ studied were prepared to build a calibration curve from which the concentration of $\mathrm{CV}$ was calculated. The amount of CV adsorbed onto the SMA at each pH studied was calculated using Eq. (4).

\subsubsection{Adsorption isotherms}

SMA adsorption experiments as a function of the initial concentration of CV were performed to obtain adsorption isotherms at different temperatures. Samples of $20.0 \mathrm{mg}$ of SMA were weighed and added to $250 \mathrm{~mL}$ Erlenmeyer flasks containing $100.0 \mathrm{~mL}$ of CV solution of a known concentration in the range of $55-175 \mathrm{mg} / \mathrm{L}$ ( $\mathrm{pH} 7.0$ ) pre-thermostated at $25,30,35,40$ and $45^{\circ} \mathrm{C}$ in a thermostatic water bath. Then, the Erlenmeyer flasks were transferred to a pre-thermostated shaker incubator and mechanically stirred at $150 \mathrm{rpm}$. The experiments were performed at the $\mathrm{pH}$ where adsorption capacity was maximal (7.0) for the time required to reach equilibrium $(12 \mathrm{~h})$. After the adsorbent was in contact with the $\mathrm{CV}$ solution, the $\mathrm{pH}$ of the suspensions was measured using a $\mathrm{pH}$ meter and no significant changes in $\mathrm{pH}$ were noticed. At the end of each experiment, the solid and liquid phases were separated by centrifugation and the concentration of $\mathrm{CV}$ in the supernatant phase was measured as described in Section 2.5.1. The amount of CV adsorbed on the SMA was calculated using Eq. (4).

\subsection{Desorption experiments}

The desorption study was carried out to access the possibility of reusing the SMA adsorbent material and recovering the CV dye. Samples of $20.0 \mathrm{mg}$ of SMA were loaded with a CV solution of $180 \mathrm{mg} / \mathrm{L}$ at $\mathrm{pH} 7.0$ for $12 \mathrm{~h}$ (optimal parameters determined from adsorption studies). Samples of SMA loaded with CV were recovered by centrifugation, washed with an excess of distilled water to remove CV not adsorbed on SMA, dried in an oven at $50{ }^{\circ} \mathrm{C}$ for $24 \mathrm{~h}$, and weighed. Dried samples of $20.0 \mathrm{mg}$ of SMA loaded with CV were weighed and transferred to $250 \mathrm{~mL}$ Erlenmeyer flasks containing $100.0 \mathrm{~mL}$ of aqueous desorption solutions of 0.1 and $1.0 \mathrm{~mol} / \mathrm{L} \mathrm{CH}_{3} \mathrm{COOH}$ or 0.01 and $0.1 \mathrm{~mol} / \mathrm{L} \mathrm{HCl}$. The Erlenmeyer flasks were mechanically stirred in a shaker incubator at $25^{\circ} \mathrm{C}$ at a speed of $150 \mathrm{rpm}$ for different time intervals, either 3 , 6,12 or $24 \mathrm{~h}$, to determine the equilibrium time of desorption. At the end of each period of time, the solid and liquid phases were separated by centrifugation. The SMA adsorbent was washed with an excess of distilled water to remove the desorption solution and dried at $50^{\circ} \mathrm{C}$ for $24 \mathrm{~h}$ and weighed. Standard aqueous solutions of $\mathrm{CV}$ were prepared for each desorption solution to build a calibration curve from which the concentration of CV was calculated. The concentration of $\mathrm{CV}$ in the supernatant phase was determined as described in Section 2.5.1. Based on their higher desorption efficiencies, the $1.0 \mathrm{~mol} / \mathrm{L} \mathrm{CH}_{3} \mathrm{COOH}$ and $0.01 \mathrm{~mol} / \mathrm{L}$ $\mathrm{HCl}$ aqueous solutions and an equilibrium time for desorption of $6 \mathrm{~h}$ were used for subsequent desorption experiments with the same experimental conditions described above. The desorption efficiency, $E_{\mathrm{des}}$, of each desorption solution was calculated using Eq. (5).

$E_{\mathrm{des}} / \%=\left(\frac{C_{e, \mathrm{CV}} V}{Q_{T, \text { max }} w_{\mathrm{SMA}}}\right) \times 100$

where $C_{e, \mathrm{CV}}(\mathrm{mg} / \mathrm{L})$ is the equilibrium concentration of $\mathrm{CV}$ in an aqueous solution of $\mathrm{CH}_{3} \mathrm{COOH}$ or $\mathrm{HCl}, V(\mathrm{~L})$ is the volume of desorption solution, $Q_{T, \max }(\mathrm{mg} / \mathrm{g})$ is the theoretical maximum adsorption capacity calculated as $423.8 \mathrm{mg} / \mathrm{g}$ and $w_{\text {SMA }}(\mathrm{g})$ is the weight of SMA loaded with CV.

\subsubsection{Reuse of spent adsorbent after desorption}

To evaluate if the SMA adsorbent retained its capacity to adsorb CV after the desorption study, dried samples of $20.0 \mathrm{mg}$ of SMA were weighed and added to $250 \mathrm{~mL}$ Erlenmeyer flasks containing $100.0 \mathrm{~mL} 180 \mathrm{mg} / \mathrm{L} \mathrm{CV}$ solution. These experiments were performed at the $\mathrm{pH}$ of maximum adsorption capacity (7.0) for the time required to reach equilibrium $(12 \mathrm{~h})$ as determined from adsorption studies. Other procedures were the same as described in Section 2.5. The re-adsorption efficiency of SMA for a new cycle of adsorption of $\mathrm{CV}$ after regeneration was calculated using Eq. (6).

$$
\begin{aligned}
& E_{\text {re-ads }} / \%=\frac{\left\{\left[\left(w_{\mathrm{SMA}, \mathrm{CV}}-w_{\mathrm{SMA}}\right) Q_{T, \max }\right]_{\mathrm{des}}+\left(Q_{\max } w_{\mathrm{SMA}}\right)_{\mathrm{ads}}\right\} / w_{\mathrm{SMA}}}{Q_{T, \max }} \\
& \quad \times 100
\end{aligned}
$$

where $w_{\mathrm{SMA}, \mathrm{CV}}(\mathrm{g})$ is the weight of SMA loaded with $\mathrm{CV}, w_{\mathrm{SMA}}(\mathrm{g})$ is the weight of SMA after desorption (calculated using $w_{S M A, C V}$ and the desorption efficiency, $\left.E_{\mathrm{des}}\right), Q_{\mathrm{T}, \max }(\mathrm{mg} / \mathrm{g})$ is the theoretical maximum adsorption capacity $(423.8 \mathrm{mg} / \mathrm{g})$ and $Q_{\max }(\mathrm{mg} / \mathrm{g})$ is the new maximum adsorption capacity after re-adsorption using regenerated SMA. 

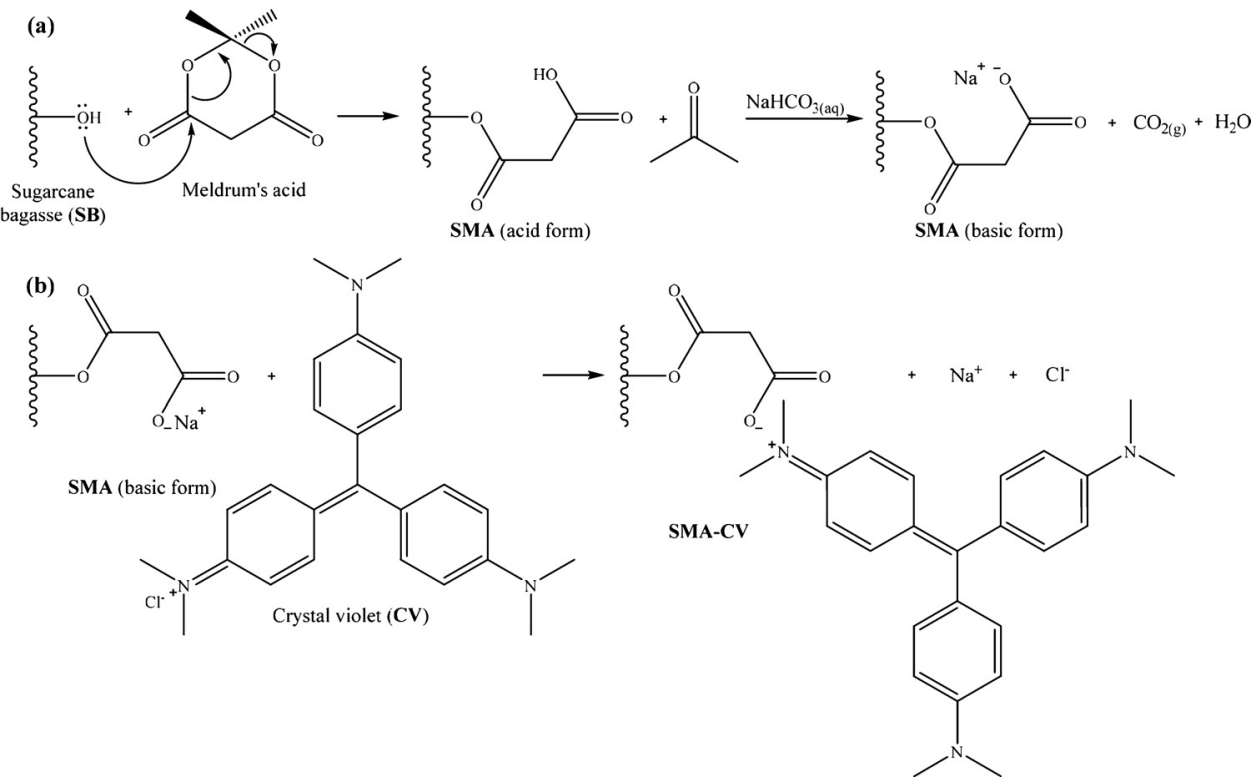

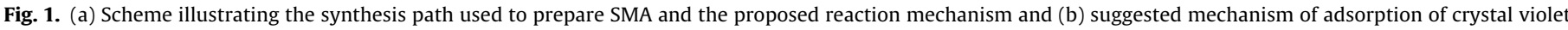
(CV) onto SMA adsorbent at $\mathrm{pH} 7$.

\section{Results and discussion}

\subsection{Synthesis and characterization of SMA}

\subsubsection{Percent weight gain ( $p w g$ ) and number of carboxylic acid} $\left(n_{\mathrm{COOH}}\right)$ and carboxylate $\left(n_{\mathrm{COO}^{-}}\right)$groups

Fig. 1 illustrates the synthesis path used to prepare the SMA adsorbent, the proposed reaction mechanism, and a suggested mechanism for adsorption of crystal violet (CV) onto SMA. The chemical modification studies of sugarcane bagasse with Meldrum's acid to obtain SMA were divided into two parts in order to optimize both $p w g$ and $n_{\mathrm{COOH}}$. In the first part, the chemical modification of sugarcane bagasse as a function of reaction time was evaluated. In the second part the chemical modification of sugarcane bagasse as a function of the amount of Meldrum's acid was performed using the shortest reaction time $(4 \mathrm{~h})$ corresponding to the highest pwg obtained in the first part. The obtained results are shown in Table 1 . As can be seen in Table 1, little variations in $p w g$ and $n_{\mathrm{COOH}}$ were noticed after a reaction time of $4 \mathrm{~h}$. Therefore, a reaction time of $4 \mathrm{~h}$ was chosen for the subsequent studies involving varying the amount of Meldrum's acid. In these studies, it was observed that as the amount of Meldrum's acid was increased, the pwg also increased. Thus, the optimized reaction

Table 1

Results of optimization of the chemical modification of sugarcane bagasse with Meldrum's acid.

\begin{tabular}{llll}
\hline Reaction time $(\mathrm{h})$ & Meldrum's acid $(\mathrm{g})$ & \multicolumn{2}{l}{$\mathrm{SMA}^{\mathrm{a}}$} \\
\cline { 3 - 4 } & & $p w g(\%)$ & $n_{\mathrm{COOH}}(\mathrm{mmol} / \mathrm{g})$ \\
\hline 1 & & 20.0 & $1.19 \pm 0.05$ \\
2 & & 29.0 & $1.55 \pm 0.10$ \\
4 & 0.5 & 45.8 & $2.19 \pm 0.05$ \\
6 & & 46.2 & $2.20 \pm 0.05$ \\
12 & & 45.9 & $2.19 \pm 0.00$ \\
24 & 0.5 & 46.2 & $2.21 \pm 0.10$ \\
& 1.0 & 20.0 & $1.19 \pm 0.05$ \\
4 & 1.5 & 62.3 & $3.71 \pm 0.20$ \\
& 2.0 & 74.0 & $3.96 \pm 0.05$ \\
& 3.0 & 82.4 & $4.35 \pm 0.10$ \\
& & 86.0 & $4.69 \pm 0.20$ \\
\hline
\end{tabular}

a The weight of sugarcane bagasse used in all chemical modifications was $0.5 \mathrm{~g}$. conditions chosen to produce the SMA adsorbent for the adsorption experiments were a sugarcane bagasse:Meldrum's acid ratio of $1: 6(\mathrm{w} / \mathrm{w})$ and a reaction time of $4 \mathrm{~h}$.

The number of carboxylate groups $\left(n_{\mathrm{COO}^{-}}\right)$was only determined for SMA produced for adsorption studies using the optimized reaction conditions (sugarcane bagasse:Meldrum's acid ratio of 1:6 $(\mathrm{w} / \mathrm{w})$ and a reaction time of $4 \mathrm{~h})$. The concentration of $n_{\mathrm{COO}}-$ was determined to be $2.65 \pm 0.01 \mathrm{mmol} / \mathrm{g}$.

\subsubsection{Elemental analysis and FTIR spectroscopy}

Elemental analysis was carried out for raw sugarcane bagasse (SB) and SMA (in acidic form) obtained from the optimized reaction conditions. Their contents of carbon, hydrogen, nitrogen and oxygen were found to be 44.05 and $43.60 \%, 6.00$ and $2.21 \%, 0.13$ and $0.00 \%$ and 49.82 and $54.20 \%$, respectively. Oxygen content was obtained indirectly by difference. Raw sugarcane bagasse (SB) and SMA in the acidic and basic forms were also characterized by FTIR spectroscopy. Fig. 2 shows the FTIR spectra for SB and SMA in its

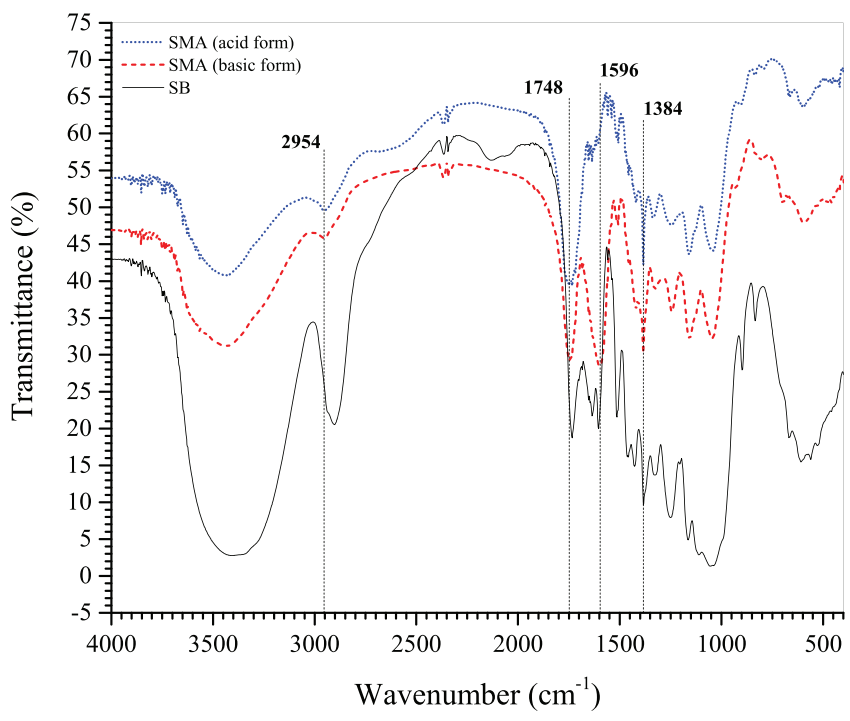

Fig. 2. FTIR spectra of SB, SMA in basic and acidic forms. 
Table 2

Thermogravimetric data for thermal decomposition of SB and SMA (in basic and acidic forms)

\begin{tabular}{lrcc}
\hline & \multicolumn{1}{c}{ SB } & SMA (basic form) & SMA (acid form) \\
\hline$T_{\mathrm{D}, 1}\left({ }^{\circ} \mathrm{C}\right)$ & 32.3 & 45.3 & 42.2 \\
$\Delta M_{1}(\%)$ & 6.5 & 6.8 & 4.9 \\
$T_{\mathrm{D}, 2}\left({ }^{\circ} \mathrm{C}\right)$ & 316.3 & 219.4 & 206.9 \\
$\Delta M_{2}(\%)$ & 38.7 & 13.0 & 16.2 \\
$T_{\mathrm{D}, 3}\left({ }^{\circ} \mathrm{C}\right)$ & 365.7 & 284.1 & 350.5 \\
$\Delta M_{3}(\%)$ & 43.4 & 31.5 & 59.8 \\
$T_{\mathrm{D}, 4}\left({ }^{\circ} \mathrm{C}\right)$ & - & - & - \\
$\Delta M_{4}(\%)$ & 11.1 & 14.9 & 10.5 \\
\hline
\end{tabular}

basic and acidic forms, respectively. The major changes that can be noticed in the FTIR spectrum for SB in relation to SMA (in its basic and acidic forms) are: (1) the appearance of bands at $2954 \mathrm{~cm}^{-1}$ for both SMA forms, corresponding to asymmetric stretching of methylene groups $\left(\mathrm{CH}_{2}\right)$ owing to the grafting of a malonyl group onto SB; (2) strong bands arising at $1748 \mathrm{~cm}^{-1}$ for both forms of SMA, corresponding to asymmetric and symmetric stretching of ester groups introduced in the esterification of malonic acid and SB and (3) bands arising at 1596 and $1384 \mathrm{~cm}^{-1}$ for SMA in the basic form, corresponding to asymmetric and symmetric stretching of carboxylate groups $\left(-\mathrm{COO}^{-} \mathrm{Na}^{+}\right)$. These changes in the FTIR spectra of SMA in its basic and acidic forms in relation to the FTIR spectrum of SB confirm that the malonyl groups were grafted onto sugarcane bagasse with success. Similar band assignments were reported by Nada and Hassan (2006), Liu et al. (2008), and Gurgel et al. (2008) for esterification of sugarcane bagasse with succinic anhydride.

\subsubsection{Thermogravimetric analysis (TGA)}

Thermogravimetric and DTG curves for SB and SMA (in its basic and acidic forms) are shown in Supplementary Figure 1. Thermogravimetric data for the thermal decomposition of SB and SMA (in basic and acid forms) are shown in Table 2. As can be seen in Supplementary Figure 1 and Table 2, the initial small weight loss that occurred at temperatures between 32 and $45^{\circ} \mathrm{C}$, corresponding to about $5-7 \%$ of the total weight loss, was attributed to the vaporization of bound water in the samples. According to Varhegyi et al. (1989), the pyrolysis of sugarcane bagasse at $10^{\circ} \mathrm{C} / \mathrm{min}$ results in two major peaks at 310 and $370^{\circ} \mathrm{C}$. These observations are in good agreement with the results shown in Table 2. Varhegyi et al. (1989) confirmed that the thermal decomposition of a lignocellulosic material may represent a superposition of the decomposition behavior of its individual components. The lignin component undergoes a slow charring process whereas the polysaccharides break down more quickly to provide volatile products. Thus, the DTG peaks at $T_{\mathrm{D}, 2}\left(316.3^{\circ} \mathrm{C}\right)$ and $T_{\mathrm{D}, 3}\left(365.7^{\circ} \mathrm{C}\right)$ may be attributed to the decomposition of hemicellulose and cellulose, respectively. The tailing portion of the sugarcane bagasse TG curve above $400^{\circ} \mathrm{C}$ reflects the slower charring over a broad temperature region of the lignin component (Varhegyi et al., 1989). In comparison with SB, SMA (in its basic and acidic forms) showed lower thermal stability, as can be seen in Table 2. DTG curves (Supplementary Figure 1) for SB and SMA show that SB exhibited second and third DTG peaks at 316.3 and $365.7^{\circ} \mathrm{C}$, whereas SMA in its basic and acidic forms showed DTG peaks at 219.4 and $284.1^{\circ} \mathrm{C}$, and 206.9 and $350.5^{\circ} \mathrm{C}$, respectively. These results demonstrate that malonylation of sugarcane bagasse decreases its thermal stability. A similar behavior was reported by Nada and Hassan (2006), who studied the thermal decomposition of succinylated bagasse. The thermal decomposition of succinylated bagasse exhibited three DTG peaks at 251,319 and $417^{\circ} \mathrm{C}$.

\subsubsection{Point of zero charge $\left(\mathrm{pH}_{\mathrm{PZC}}\right)$}

The $\mathrm{pH}$ at the point of zero charge $\left(\mathrm{pH}_{\mathrm{PZC}}\right)$ was used to characterize the properties of the SMA surface (in its basic form). In fact, the $\mathrm{pH}$ required to give a net zero surface charge is related to the acidity constant or ionization constant of an adsorbent (Noh and Schwarz, 1990). Thus, an adsorbent surface has a net positive charge at $\mathrm{pH}<\mathrm{pH}_{\mathrm{PZC}}$, whereas at $\mathrm{pH}>\mathrm{pH}_{\mathrm{PZC}}$ it has a net negative charge. Therefore, the adsorption of cationic species such as crystal violet is favored under the latter condition. The $\mathrm{pH}_{\mathrm{PZC}}$ of the SMA adsorbent was found to be $4.78 \pm 0.03$. This value of $\mathrm{pH}_{\mathrm{PZC}}$ suggests that when the $\mathrm{pH}$ of a crystal violet solution is higher than 4.78 , the SMA adsorbent will have a net negative surface charge that can attract positively charged crystal violet (CV) dye molecules.

Compared to SMA, sugarcane bagasse modified with succinic anhydride (SBC 2), reported by Gusmao et al. (2012), showed a $\mathrm{pH}_{\text {PZC }}$ of 5.26. This difference can be attributed to the malonyl group, which has one methylene group between the carbonyl groups in comparison with the succinyl group that has two methylene groups. This difference gives the malonyl group a lower $\mathrm{pH}_{\mathrm{PZC}}$.

\subsubsection{Scanning electron microscopy (SEM)}

SEM was used to assess the morphological features and surface characteristics of the SMA adsorbent material. SEM micrographs were also used to determine the morphological changes in fiber structure and surface that occur due to the chemical modification and adsorption of CV onto SMA.

3.1.5.1. Morphology of SB, SMA and CV-loaded SMA. Fig. 7 shows SEM micrographs of SB and SMA (before and after adsorption of $\mathrm{CV})$ at $200(\mathrm{a}-\mathrm{c})$ and $1000(\mathrm{~d}-\mathrm{f})$ fold magnification, respectively. As can be seen in Fig. 7a, the raw sugarcane bagasse (SB) particles have a great variety of shapes and sizes, characterizing the great heterogeneity of the starting material after the milling process. The micrograph shown in Fig. $7 \mathrm{~b}$ reveals that a reduction in the size of the particles occurred after chemical modification of the SB with Meldrum's acid to produce SMA. Another apparent reduction in the size of the particles can be noticed in Fig. 7c after adsorption of CV onto the SMA ( $180 \mathrm{mg} / \mathrm{L} \mathrm{CV}, \mathrm{pH} 7.0$ and equilibrium time of $12 \mathrm{~h}$ ). Comparing the micrographs in Fig. $7 \mathrm{~d}$ and e, it is possible to observe that the chemical modification process increased the number of pores and cracks on the fiber surface. SEM micrographs of SMA before and after adsorption of CV are shown in Fig. 7d and e, respectively. In comparison with SMA before adsorption, SMA after adsorption showed various important changes: (1) the adsorption of CV onto the SMA led to the formation of a monolayer of CV molecules over the surface of the SMA (molecular cloud of uniform thickness), which can be visualized by the smoothing of the SMA's surface and (2) various pores and cracks characteristics of the SMA before adsorption were filled by CV molecules, showing the adherent surface of the SMA adsorbent (Kaur et al., 2013; Kumar and Ahmad, 2011).

\subsection{Adsorption studies}

\subsubsection{Effect of adsorbent dosage on CV adsorption}

Fig. 3 illustrates the removal of crystal violet (CV) as a function of SMA dosage. The CV removal efficiency increased as adsorbent dosage increased as a consequence of the increase in available adsorption sites. However, the amount of CV adsorbed per unit weight of SMA $\left(q_{e}\right)$ decreased with increasing SMA adsorbent weight due to the decrease in the adsorbate/adsorbent ratio. Similar results were observed by Nunes et al. (2011) for adsorption of methylene blue (MB) on a Raphanus sativus press cake adsorbent obtained by carbonization in a microwave oven. Based on this result, the following adsorption experiments were performed with 


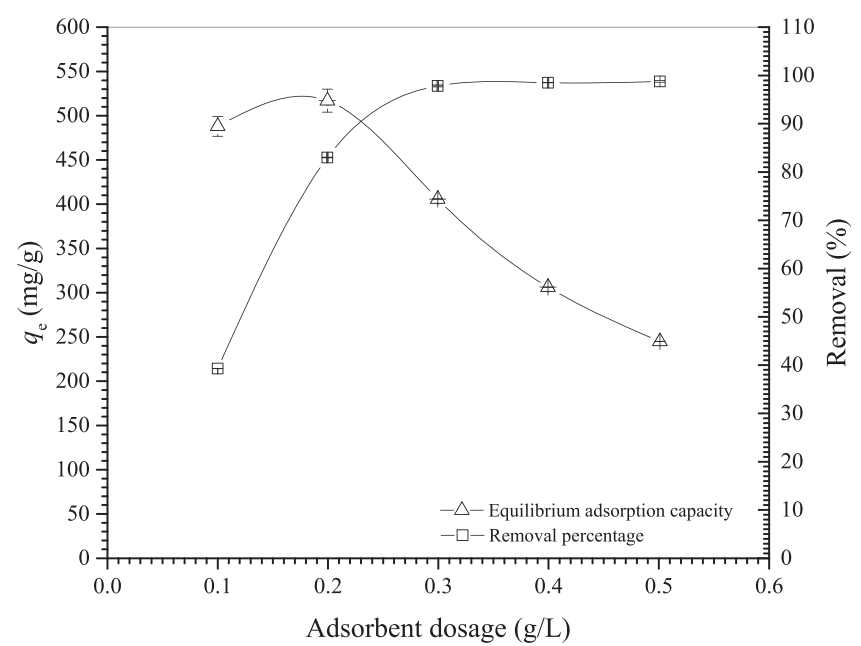

Fig. 3. Effect of SMA adsorbent dosage on CV adsorption performance $(125 \mathrm{mg} / \mathrm{L} \mathrm{CV}$, $150 \mathrm{rpm}, 25^{\circ} \mathrm{C}$ and $12 \mathrm{~h}$ of shaking).

an adsorbent dosage of $0.20 \mathrm{~g} / \mathrm{L}$, because higher dosages led to a significant decrease in adsorption capacity.

\subsubsection{Effect of solution $\mathrm{pH}$ on $\mathrm{CV}$ adsorption}

The effect of $\mathrm{pH}$ on $\mathrm{CV}$ adsorption was investigated at $25^{\circ} \mathrm{C}$ with a $200 \mathrm{mg} / \mathrm{L}$ CV solution and $0.2 \mathrm{~g} / \mathrm{L}$ adsorbent. Fig. 4 shows the adsorption of CV on the SMA adsorbent as a function of solution $\mathrm{pH}$ from 3 to 9 . The $\mathrm{pH}_{\mathrm{PZC}}$ of the SMA adsorbent was found to be 4.78. Thus, the adsorption of cationic species such as CV is favored at $\mathrm{pH}>\mathrm{pH}_{\mathrm{PZC}}$, where the SMA adsorbent has a net negative charge. The $\mathrm{p} K_{\mathrm{a}}$ 's for the loss of the two protons of $\mathrm{CV}$ are approximately 1.15 and 1.8 (Fayoumi et al., 2012). According to Cotoruelo et al. (2012), at $\mathrm{pH}$ values between 0 and 2, CV is in the form of $\mathrm{CV}^{3+} \cdot 3 \mathrm{Cl}^{-}$, from 2 to $9 \mathrm{CV}$ is in the form of $\mathrm{CV}^{2+} \cdot 2 \mathrm{Cl}^{-}$and $\mathrm{CV}^{+} \mathrm{Cl}^{-}$and at a $\mathrm{pH}$ above $9 \mathrm{CV}$ is in the form of $\mathrm{CV}-\mathrm{OH}$. Thus, in the present study the most probable forms of $\mathrm{CV}$ in the aqueous solutions are $\mathrm{CV}^{2+} \cdot 2 \mathrm{Cl}^{-}$and $\mathrm{CV}^{+} \mathrm{Cl}^{-}$. As can be seen in Fig. 4, the adsorption capacity increased as the $\mathrm{pH}$ was increased, and reached a plateau at $\mathrm{pH}$ values between 7 and 9 . At low $\mathrm{pH}$ values $(\mathrm{pH}<4)$, protonation of the carboxylate groups on the surface of the SMA adsorbent took place and decreased the adsorption capacity. At $\mathrm{pH}$ values higher than $\mathrm{pH}_{\mathrm{PZC}}$ (4.78), an increase in adsorption capacity

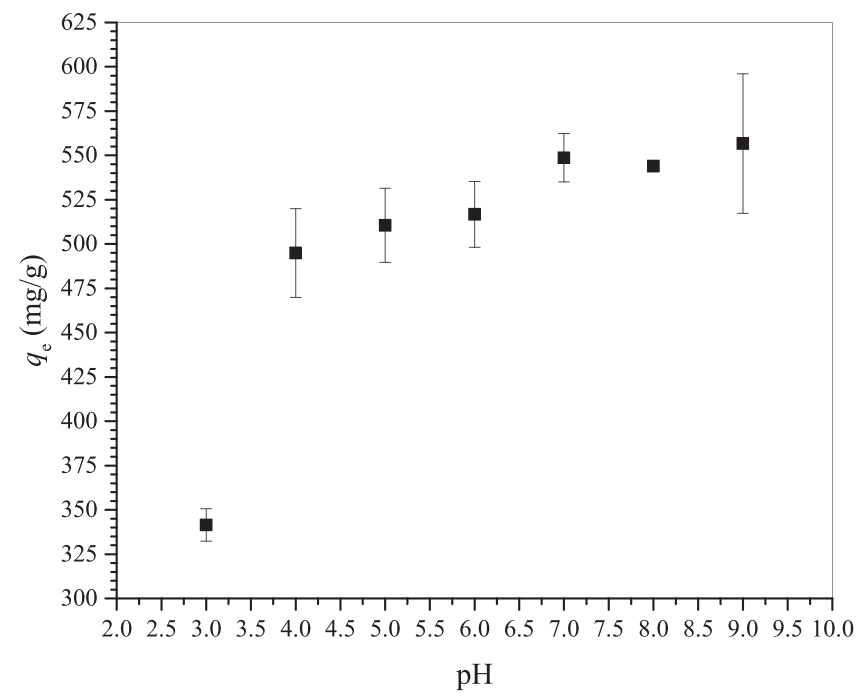

Fig. 4. Effect of $\mathrm{pH}$ on adsorption of CV on the SMA adsorbent $(200 \mathrm{mg} / \mathrm{LCV}, 150 \mathrm{rpm}$, $25^{\circ} \mathrm{C}$ and $12 \mathrm{~h}$ of shaking). was observed due to the strong electrostatic attraction between the negatively charged carboxylate groups on the SMA adsorbent surface and protonated CV molecules. Further increases in $\mathrm{pH}$ had no significant effect on the adsorption capacity of SMA. Thus, pH 7.0 was considered an optimum $\mathrm{pH}$ for the subsequent dye adsorption studies.

\subsubsection{Adsorption kinetics}

Adsorption kinetics is a very important parameter for designing adsorption systems and is required in order to select optimum operating conditions for batch adsorption process (Kaur et al., 2013). Three adsorption kinetic models were used to model the adsorption rate of CV on the SMA adsorbent.

The pseudo-first-order kinetic model of Lagergren (1898) describes the adsorption rate based on adsorption capacity. It can be presented as follows:

$\frac{d q_{t}}{d t}=k_{1}\left(q_{e}-q_{t}\right)$

where $q_{e}$ and $q_{t}(\mathrm{mg} / \mathrm{g})$ are the adsorption capacities at equilibrium $t_{e}$ and time $t(\mathrm{~min})$, respectively, and $k_{1}\left(\mathrm{~min}^{-1}\right)$ is the pseudofirst-order rate constant for the kinetic model. Rearranging and integrating Eq. (7) with the boundary conditions of $q_{t}=0$ at $t=0$ and $q_{t}=q_{t}$ at $t=t$, yields:

$q_{t}=q_{e}\left(1-\exp ^{-k_{1} t}\right)$

The pseudo-second-order kinetic model of Ho and McKay (1998) also describes adsorption based on adsorption capacity. It considers that the rate limiting step may be chemical adsorption involving valent forces. It can be presented as follows:

$$
\frac{d q_{t}}{d t}=k_{2}\left(q_{e}-q_{t}\right)^{2}
$$

where $q_{e}$ and $q_{t}(\mathrm{mg} / \mathrm{g})$ are the adsorption capacities at equilibrium $t_{e}$ and time $t$ ( $\left.\mathrm{min}\right)$, respectively, and $k_{2}(\mathrm{~g} / \mathrm{mg} \mathrm{min})$ is the pseudosecond-order rate constant for the kinetic model. Rearranging and integrating Eq. (9) with the boundary conditions of $q_{t}=0$ at $t=0$ and $q_{t}=q_{t}$ at $t=t$, yields:

$q_{t}=\frac{k_{2} q_{e}^{2} t}{1+k_{2} q_{e} t}$

The best model fit was evaluated based on values of the determination coefficients and the difference between values of calculated $\left(q_{t, \text { calc }}\right)$ and experimental $\left(q_{t, \text { exp }}\right)$ adsorption capacities by means of a root mean square (RMS) error analysis (Nunes et al., 2011) as follows:

RMS $=\frac{\sqrt{\sum_{i=1}^{N}\left[\left(q_{t, \text { calc }}-q_{t, \exp }\right) / q_{t, \exp }\right]^{2}}}{N}$

where $N$ corresponds to the number of experimental points. Taking into account that the models provide a calculated $q_{e}$, the percentage difference between the calculated and experimental $q_{e}$ values was also evaluated.

The results obtained from the nonlinear regression analysis of the pseudo-first-order and pseudo-second-order kinetic models using Microcal Origin 9.1 ${ }^{\mathrm{TM}}$ set to use the Levenberg Marquardt iteration algorithm and weights as statistics are shown in Table 3 (experimental kinetic data available in Supplementary Table 1). Fig. 5a shows plots of $q_{t}$ against $t$ for pseudo-first-order and pseudosecond-order models. As can be seen in Table $3, R^{2}$ values obtained from the pseudo-first-order model were lower in comparison with the pseudo-second-order model. Furthermore, the values of $q_{e \text {,calc }}$ were underestimated in comparison with the values of $q_{e, \text { exp }}$. From evaluating the values of $R^{2}$ and RMS and comparing $q_{e, \exp }$ and $q_{e \text {,calc }}$ for the pseudo-second-order kinetic model, it was possible to conclude that this model can describe the adsorption of 
Table 3

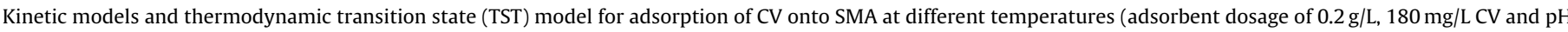
7.0).

\begin{tabular}{|c|c|c|c|c|}
\hline \multirow[t]{2}{*}{ Parameters } & \multicolumn{4}{|l|}{ Temperature $\left({ }^{\circ} \mathrm{C}\right)$} \\
\hline & $25(298.15 \mathrm{~K})$ & $35(308.15 \mathrm{~K})$ & 45 (318.15 K) & $55(328.15 \mathrm{~K})$ \\
\hline $\begin{array}{l}q_{e, \exp }(\mathrm{mg} / \mathrm{g}) \\
\text { Pseudo-first-order }\end{array}$ & $545.8 \pm 14.3$ & $671.7 \pm 6.2$ & $758.2 \pm 7.6$ & $875.1 \pm 0.4$ \\
\hline $\begin{array}{l}q_{e, \text { calc }}(\mathrm{mg} / \mathrm{g}) \\
k_{1}\left(\mathrm{~min}^{-1}\right) \\
R^{2} \\
\chi^{2} \\
\text { RMS }\end{array}$ & $\begin{array}{l}500.8 \pm 14.9 \\
(3.16 \pm 0.41) \times 10^{-2} \\
0.7641 \\
2.602 \\
0.0216\end{array}$ & $\begin{array}{l}620.1 \pm 20.0 \\
(3.78 \pm 0.57) \times 10^{-2} \\
0.6821 \\
3.4107 \\
0.0225\end{array}$ & $\begin{array}{l}720.5 \pm 18.6 \\
(3.47 \pm 0.42) \times 10^{-2} \\
0.7611 \\
2.9326 \\
0.0197\end{array}$ & $\begin{array}{l}834.5 \pm 16.5 \\
(4.15 \pm 0.47) \times 10^{-2} \\
0.7275 \\
2.4455 \\
0.0155\end{array}$ \\
\hline $\begin{array}{l}\text { Pseudo-second-ord } \\
q_{e, \text { calc }}(\mathrm{mg} / \mathrm{g}) \\
q_{e, \text { calc }}(\mathrm{mmol} / \mathrm{g}) \\
k_{2}(\mathrm{~g} / \mathrm{mg} \mathrm{min}) \\
k_{2}(\mathrm{~g} / \mathrm{mol} \mathrm{min}) \\
R^{2} \\
\chi^{2} \\
\text { RMS }\end{array}$ & $\begin{array}{l}552.7 \pm 10.8 \\
1.48 \pm 0.03 \\
(8.20 \pm 0.99) \times 10^{-5} \\
30.55 \pm 3.67 \\
0.9387 \\
0.6760 \\
0.0115\end{array}$ & $\begin{array}{l}673.8 \pm 16.2 \\
1.81 \pm 0.04 \\
(1.00 \pm 0.17) \times 10^{-4} \\
37.25 \pm 6.51 \\
0.9007 \\
1.0650 \\
0.0126\end{array}$ & $\begin{array}{l}746.8 \pm 17.8 \\
2.00 \pm 0.05 \\
(1.21 \pm 0.26) \times 10^{-4} \\
45.08 \pm 9.73 \\
0.8706 \\
1.5883 \\
0.0144\end{array}$ & $\begin{array}{l}862.0 \pm 14.4 \\
2.31 \pm 0.04 \\
(1.37 \pm 0.26) \times 10^{-4} \\
51.04 \pm 9.76 \\
0.8757 \\
1.1156 \\
0.0106\end{array}$ \\
\hline $\begin{array}{l}\text { Intraparticle diffusi } \\
\text { Step } 1\end{array}$ & & & & \\
\hline $\begin{array}{l}k_{i d}\left(\mathrm{mg} / \mathrm{g} \mathrm{min}^{1 / 2}\right) \\
C(\mathrm{mg} / \mathrm{g}) \\
R^{2}\end{array}$ & $\begin{array}{l}20.65 \pm 1.52 \\
237.0 \pm 12.4 \\
0.9786\end{array}$ & $\begin{array}{l}37.13 \pm 6.00 \\
251.5 \pm 39.87 \\
0.9491\end{array}$ & $\begin{array}{l}27.25 \pm 2.12 \\
375.73 \pm 17.24 \\
0.9762\end{array}$ & $\begin{array}{l}21.18 \pm 2.46 \\
544.68 \pm 22.51 \\
0.9360\end{array}$ \\
\hline $\begin{array}{l}\text { Step } 2 \\
k_{\text {id }}\left(\mathrm{mg} / \mathrm{g} \min ^{1 / 2}\right) \\
C(\mathrm{mg} / \mathrm{g}) \\
R^{2}\end{array}$ & $\begin{array}{l}5.62 \pm 0.82 \\
404.5 \pm 16.5 \\
0.9200\end{array}$ & $\begin{array}{l}12.14 \pm 1.38 \\
434.4 \pm 21.20 \\
0.9382\end{array}$ & $\begin{array}{l}5.11 \pm 0.82 \\
647.35 \pm 15.02 \\
0.9263\end{array}$ & $\begin{array}{l}3.01 \pm 0.64 \\
803.21 \pm 12.88 \\
0.8756\end{array}$ \\
\hline $\begin{array}{l}\text { Eyring (TST) } \\
\Delta_{\mathrm{ads}} G^{\ddagger}(\mathrm{kJ} / \mathrm{mol}) \\
\Delta_{\mathrm{ads}} H^{\ddagger}(\mathrm{kJ} / \mathrm{mol}) \\
\Delta_{\mathrm{ads}} S^{\ddagger}(\mathrm{J} / \mathrm{Kmol}) \\
R^{2} \\
\chi^{2}\end{array}$ & $\begin{array}{l}64.52 \pm 9.51 \\
11.45 \pm 0.80 \\
-178.00 \pm 23.13 \\
0.9856 \\
2.32 \times 10^{-4}\end{array}$ & $\begin{array}{l}66.30 \pm 9.77 \\
- \\
- \\
- \\
-\end{array}$ & $\begin{array}{l}68.08 \pm 10.03 \\
- \\
- \\
- \\
-\end{array}$ & $\begin{array}{l}69.86 \pm 10.30 \\
- \\
- \\
- \\
-\end{array}$ \\
\hline
\end{tabular}

CV onto SMA satisfactorily. However, this model assumes that chemisorption may be the rate-controlling mechanism by which CV is adsorbed by SMA, based on the thermodynamic parameters and activation energy, it was suggested that the adsorption mechanism controlling the adsorption of CV dye molecules on SMA adsorbent is physical adsorption as will be presented and discussed later. In addition, both values of $q_{e, \text { calc }}$ and $k_{2}$ increased as the temperature was increased, indicating that an increase in temperature favors the adsorption process. Similar results were noted by Kaur et al. (2013) for CV adsorption by Eichhornia charcoal (EC).

An intraparticle diffusion (Weber and Morris, 1963) model was used to determine the diffusion mechanism and the intraparticle diffusion rate constant. It can be presented as follows:

$q_{t}=k_{i d} t^{1 / 2}+C$

where $k_{i d}\left(\mathrm{mg} / \mathrm{g} \mathrm{min}^{1 / 2}\right)$ is the intraparticle diffusion rate constant and $C(\mathrm{mg} / \mathrm{g})$ gives an idea of the thickness of the boundary layer, i.e. the larger the intercept, the greater the boundary layer effect. From the plot of $q_{t}$ against $t^{1 / 2}$, the value of $k_{i d}$ can be obtained as the slope and $C$ as the intercept (Fig. 5b). If the plot of $q_{t}$ against $t^{1 / 2}$ gives a linear relationship with the experimental data, then the adsorption process is found to be controlled by intraparticle diffusion only. Conversely, if the experimental data seems to be better described by multilinear plots, two or more steps may be influencing the adsorption process. The results obtained by linear regression analyses of the experimental data are shown in Table 3. As can be seen in Fig. 5b, the experimental data exhibited similar overall features of multilinear plots with two steps. The first step is attributed to the diffusion of CV through the solution to the external surface of the SMA adsorbent or to boundary layer diffusion of solute molecules (Kaur et al., 2013; Nunes et al., 2011). The second step is considered the intraparticle diffusion mechanism, where diffusion starts to slow down due to the low concentration of CV remaining in the solution (Kaur et al., 2013; Nunes et al., 2011). As the plots did not cross the origin $(C \neq 0)$, it suggests that some boundary layer control contributes to the adsorption process, confirming that intraparticle diffusion is not the only rate-limiting step.

The pseudo-second-order kinetic rate constant, $k_{2}$, was used to calculate the Arrhenius activation energy, $E_{a}$, for the adsorption of CV on the SMA adsorbent as follows:

$\ln k_{2}=\ln A-\frac{E_{a}}{R T}$

where $k_{2}(\mathrm{~g} / \mathrm{mol} \mathrm{min})$ is the pseudo-second-order rate constant, $A$ is the pre-exponential factor related to the frequency of collisions $\left(\mathrm{min}^{-1}\right), R$ is the ideal gas constant $(8.314 \mathrm{~J} / \mathrm{K} \mathrm{mol}), T(\mathrm{~K})$ is the absolute temperature and $E_{a}(\mathrm{~kJ} / \mathrm{mol})$ is the Arrhenius activation energy. $E_{a}$ and $A$ were obtained from the plot of $\ln k_{2}$ against $1 / T$ (Supplementary Figure 2a). The values of $E_{a}$ and $A$ for adsorption of CV on SMA were found to be $14.14 \pm 0.74 \mathrm{~kJ} / \mathrm{mol}$ and $9.26 \times 10^{3} \pm 2.64 \times 10^{3} \mathrm{~min}^{-1}$, respectively. The magnitude of the activation energy may give an idea about the type of adsorption, i.e. physical or chemical adsorption. Lower values of $E_{a}(<40 \mathrm{~kJ} / \mathrm{mol})$ are associated with physical adsorption, whereas higher values of $E_{a}(>40 \mathrm{~kJ} / \mathrm{mol})$ indicate chemical adsorption (Anirudhan and Radhakrishnan, 2008). Furthermore, according to Saha et al. (2012), an ion-exchange process is characterized by values of $E_{a}$ between 8 and $16 \mathrm{~kJ} / \mathrm{mol}$. Therefore, the value of $E_{a}$ for $\mathrm{CV}$ adsorption onto SMA suggests physical adsorption and a mechanism governed by an ion-exchange process (Fig. 1). 

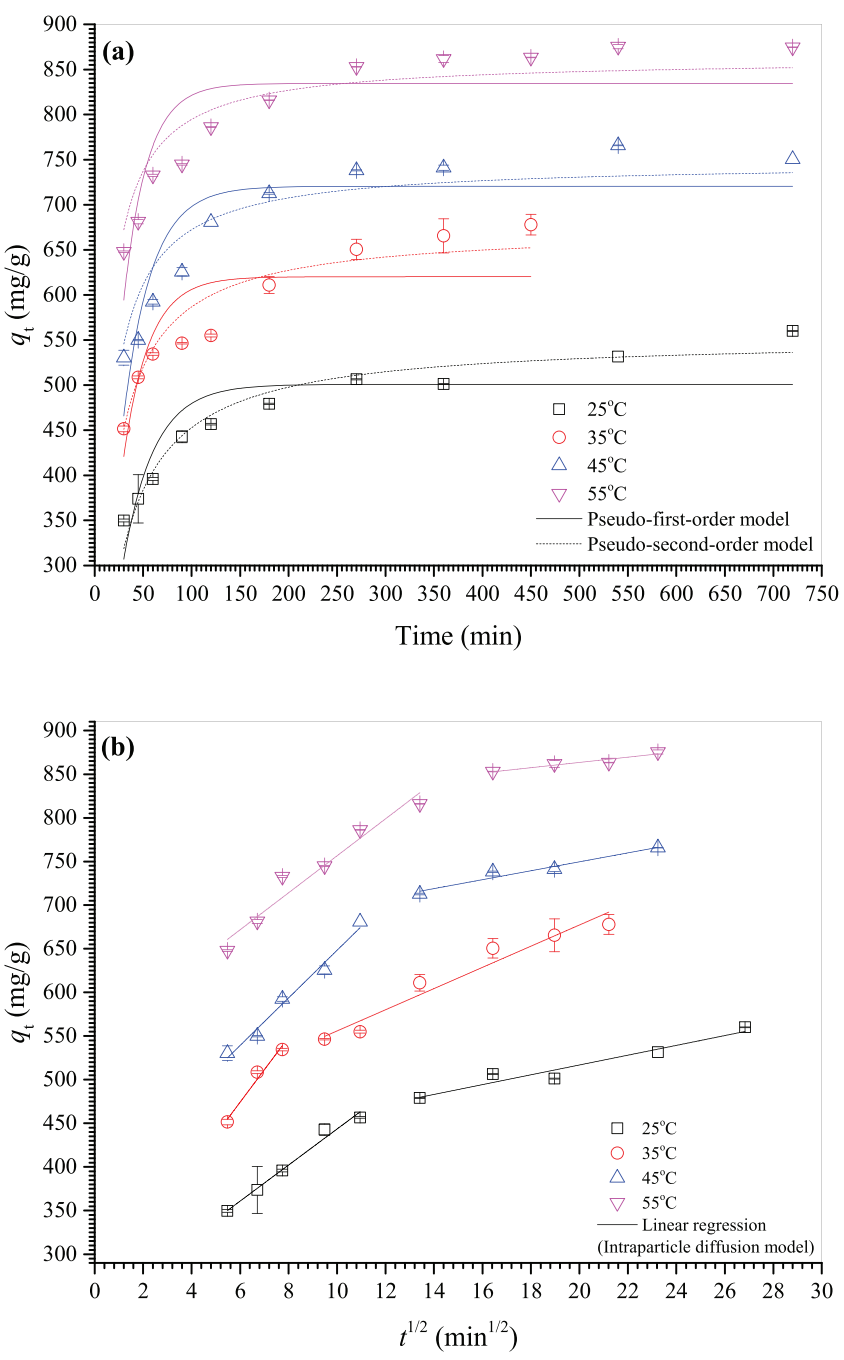

Fig. 5. Adsorption kinetics of CV onto SMA at pH 7.0 and $180 \mathrm{mg} / \mathrm{L} \mathrm{CV}$ (a) pseudofirst- and pseudo-second-order kinetic models and (b) intraparticle diffusion model.

The Eyring equation for the thermodynamic transition state was used to calculate the changes in activation enthalpy $\left(\Delta_{\text {ads }} H^{\ddagger}\right)$, entropy $\left(\Delta_{\text {ads }} S^{\ddagger}\right)$ and free energy $\left(\Delta_{\text {ads }} G^{\ddagger}\right)$ as follows:

$\ln \left(\frac{k_{2}}{T}\right)=-\frac{\Delta_{\mathrm{ads}} H^{\ddagger}}{R T}+\frac{\Delta_{\mathrm{ads}} S^{\ddagger}}{R}+\ln \frac{k_{B}}{h}$

where $k_{2}(\mathrm{~g} / \mathrm{mol} \mathrm{min})$ is the pseudo-second-order rate constant, $k_{B}$ $\left(1.3807 \times 10^{-23} \mathrm{~J} / \mathrm{K}\right)$ is the Boltzmann constant, $h(6.6261 \mathrm{Js})$ is the Plank constant, $R(8.314 \mathrm{~J} / \mathrm{K} \mathrm{mol})$ is the ideal gas constant, $T(\mathrm{~K})$ is the absolute temperature, $\Delta_{\text {ads }} H^{\ddagger}(\mathrm{kJ} / \mathrm{mol})$ is the change in activation enthalpy and $\Delta_{\text {ads }} S^{\ddagger}(\mathrm{J} / \mathrm{K} \mathrm{mol})$ is the change in activation entropy for the adsorption process. The term $\ln \left(k_{\mathrm{B}} / h\right)$ is equal to 23.76. The values of $\Delta_{\text {ads }} H^{\ddagger}$ and $\Delta_{\text {ads }} S^{\ddagger}$ were obtained from linear regression and calculated from the slope and intercept of the plot of $\ln \left(k_{2} / T\right)$ against $1 / T$ (Supplementary Figure $2 \mathrm{~b}$ ).

The values of $\Delta_{\text {ads }} H^{\ddagger}$ and $\Delta_{\text {ads }} S^{\ddagger}$ were used to calculate the change in activation free energy $\left(\Delta_{\text {ads }} G^{\ddagger}\right)$ as follows:

$\Delta_{\text {ads }} G^{\ddagger}=\Delta_{\text {ads }} H^{\ddagger}-T \Delta_{\text {ads }} S^{\ddagger}$

The values of $\Delta_{\text {ads }} H^{\ddagger}, \Delta_{\text {ads }} S^{\ddagger}$ and $\Delta_{\text {ads }} G^{\ddagger}$ are presented in Table 3 . The magnitude of the $\Delta_{\text {ads }} H^{\ddagger}$ and $\Delta_{\text {ads }} S^{\ddagger}$ values reflects the transition state structure. The energy required to reorganize the involved species at the solid-liquid interface is reflected in the energy content of the activated complex and corresponds to $\Delta_{\text {ads }} H^{\ddagger}$. The positive value of $\Delta_{\mathrm{ads}} H^{\ddagger}$ reflects the energy required to reach the transition state in the adsorption process, where a layer of water molecules involved in ion-dipole interactions with the adsorbent are exchanged for a layer of CV dye molecules. It suggests that the energy released due to the adsorption process $\left(\Delta_{\text {ads }} H^{\circ}<0\right)$ (Table 4 ) is partially absorbed by the solid adsorbent while the remainder is dissipated to the surroundings. Then, the portion absorbed by the solid is probably used to reach the transition state where a CV molecule is adsorbed by an adsorbent surface site. This phenomenon probably increases the rate constant of adsorption. The negative value of $\Delta_{\text {ads }} S^{\ddagger}$ is a measure of the variation in the number of system settings to the formation of the activated complex. It may suggest that water molecules are released from the solid surface to the bulk solution while CV molecules are adsorbed by the adsorption sites, resulting in a smaller number of possible configurations for the system state with fewer degrees of freedom. As can be seen in Table $3, \Delta_{\text {ads }} G^{\ddagger}$ values become more positive with increasing temperature. Since $\Delta_{\text {ads }} G^{\ddagger}=\Delta_{\text {ads }} H^{\ddagger}-\mathrm{T} \Delta_{\text {ads }} S^{\ddagger}>0$, as the temperature increases the change in the activation free energy must increase as a consequence of the positive values of $\Delta_{\text {ads }} H^{\ddagger}$ and $\mathrm{T} \Delta_{\mathrm{ads}} S^{\ddagger}$. Also, as a consequence of the progressive formation of a monolayer, fewer adsorption sites become available, which suggests an increase in the energy barrier for adsorption of CV as the temperature is increased.

\subsubsection{Adsorption isotherms}

Adsorption isotherms describe how adsorbates interact with adsorbents. Three of the most widely used isotherms were chosen to evaluate the equilibrium adsorption data at 25, 30, 35, 40 and $45^{\circ} \mathrm{C}$ : the Langmuir, Freundlich and Langmuir-Freundlich (Sips) isotherms.

Langmuir isotherm theory (Langmuir, 1918) is based on (1) adsorption is limited to the formation of a monolayer, or the number of adsorbed species does not exceed the total surface sites; (2) all adsorption surface sites have the same affinity for the adsorbate; (3) no solute-solute or solute-solvent interactions are considered; (4) all the adsorption sites are initially unoccupied and (5) no reverse reaction of a displaced ion, such as a proton, with the adsorption site is considered. The Langmuir isotherm can be presented as follows:

$q_{e}=\frac{Q_{\max } b C_{e}}{1+b C_{e}}$

where $q_{e}(\mathrm{mg} / \mathrm{g})$ is the equilibrium adsorption capacity, $Q_{\max }(\mathrm{mg} / \mathrm{g})$ is the maximum adsorption capacity of CV per unit weight of SMA required in order to form a complete monolayer on the surface bound at a high equilibrium $\mathrm{CV}$ concentration $C_{e}(\mathrm{mg} / \mathrm{L})$, and $b$ $(\mathrm{L} / \mathrm{mg})$ is the Langmuir constant related to the affinity of the binding sites. $Q_{\max }$ represents the practical limiting adsorption capacity when the surface is fully covered with CV.

One of the essential characteristics of the Langmuir isotherm can be expressed by a separation factor, $R_{L}$; which is defined as follows:

$R_{L}=\frac{1}{1+b C_{i}}$

where $C_{i}(\mathrm{mg} / \mathrm{L})$ is the initial concentration of $\mathrm{CV}$ and $b(\mathrm{~L} / \mathrm{mg})$ is the Langmuir constant. The value of $R_{L}$ indicates if an isotherm is irreversible $\left(R_{L}=0\right)$, favorable $\left(0<R_{L}<1\right)$, linear $\left(R_{L}=1\right)$, or unfavorable $\left(R_{L}>1\right)$.

The Freundlich isotherm (Freundlich, 1906) can be applied to non-ideal adsorption on heterogeneous surfaces as well as multilayer adsorption. It can be represented as follows:

$q_{e}=K C_{e}^{1 / n}$

where $K\left[\mathrm{mg} / \mathrm{g}(\mathrm{L} / \mathrm{mg})^{1 / n}\right]$ and $n$ are the Freundlich constants. The parameter $n$ is usually greater than unity. The larger the value of 
Table 4

Isotherms and van't Hoff model for the adsorption of CV onto SMA at different temperatures (adsorbent dosage of $0.2 \mathrm{~g} / \mathrm{L}, 150 \mathrm{rpm}$, equilibrium time of $12 \mathrm{~h}$ and $\mathrm{pH} 7.0$ ).

\begin{tabular}{|c|c|c|c|c|c|c|}
\hline \multirow[t]{2}{*}{ Model } & \multirow[t]{2}{*}{ Parameters } & \multicolumn{5}{|c|}{ Temperature $\left({ }^{\circ} \mathrm{C}\right)$} \\
\hline & & $25(298.15 \mathrm{~K})$ & $30(303.15 \mathrm{~K})$ & $35(308.15 \mathrm{~K})$ & 40 (313.15 K) & $45(318.15 \mathrm{~K})$ \\
\hline- & $Q_{\text {max,exp }}(\mathrm{mg} / \mathrm{g})$ & $568.3 \pm 2.1$ & $586.5 \pm 2.0$ & $611.2 \pm 2.8$ & $645.2 \pm 3.1$ & $686.0 \pm 0.0$ \\
\hline \multirow[t]{7}{*}{ Langmuir } & $\mathrm{Q}_{\max }(\mathrm{mg} / \mathrm{g})$ & $575.4 \pm 4.8$ & $601.9 \pm 9.0$ & $633.5 \pm 17.3$ & $662.7 \pm 7.1$ & $692.1 \pm 23.4$ \\
\hline & $Q_{\max }(\mathrm{mmol} / \mathrm{g})$ & $1.41 \pm 0.01$ & $1.48 \pm 0.02$ & $1.55 \pm 0.04$ & $1.62 \pm 0.02$ & $1.70 \pm 0.06$ \\
\hline & $b(\mathrm{~L} / \mathrm{mg})$ & $1.98 \pm 0.09$ & $1.70 \pm 0.13$ & $1.55 \pm 0.17$ & $1.30 \pm 0.06$ & $1.05 \pm 0.15$ \\
\hline & $R_{L}$ & $0.009-0.003$ & $0.010-0.003$ & $0.011-0.004$ & $0.014-0.004$ & $0.014-0.005$ \\
\hline & $R^{2}$ & 0.9899 & 0.9763 & 0.9497 & 0.9919 & 0.9451 \\
\hline & $\chi^{2}$ & 0.1973 & 0.5841 & 1.4572 & 0.2717 & 1.3404 \\
\hline & RMS & 0.0062 & 0.0116 & 0.0164 & 0.0066 & 0.0300 \\
\hline \multirow[t]{5}{*}{ Freundlich } & $K(\mathrm{mg} / \mathrm{g})(\mathrm{L} / \mathrm{mg})^{1 / n}$ & $400.3 \pm 20.9$ & $400.6 \pm 23.7$ & $409.2 \pm 23.9$ & $407.5 \pm 24.1$ & $411.9 \pm 26.8$ \\
\hline & $n$ & $10.21 \pm 1.96$ & $8.95 \pm 1.81$ & $7.34 \pm 1.48$ & $7.22 \pm 1.28$ & $7.03 \pm 1.46$ \\
\hline & $R^{2}$ & 0.7571 & 0.7320 & 0.7486 & 0.7739 & 0.7712 \\
\hline & $\chi^{2}$ & 4.7524 & 6.5947 & 7.2867 & 7.5956 & 5.5893 \\
\hline & RMS & 0.0299 & 0.0352 & 0.0386 & 0.0371 & 0.0341 \\
\hline \multirow[t]{6}{*}{ Sips } & $Q_{\max }(\mathrm{mg} / \mathrm{g})$ & $566.5 \pm 2.0$ & $589.3 \pm 5.8$ & $605.9 \pm 5.4$ & $648.8 \pm 5.1$ & $698.6 \pm 18.2$ \\
\hline & $b(\mathrm{~L} / \mathrm{mg})$ & $1.75 \pm 0.03$ & $1.45 \pm 0.05$ & $1.60 \pm 0.04$ & $1.34 \pm 0.03$ & $0.87 \pm 0.05$ \\
\hline & $n$ & $0.791 \pm 0.025$ & $0.737 \pm 0.056$ & $0.638 \pm 0.039$ & $0.857 \pm 0.035$ & $0.994 \pm 0.105$ \\
\hline & $R^{2}$ & 0.9986 & 0.9923 & 0.9953 & 0.9975 & 0.9877 \\
\hline & $\chi^{2}$ & 0.0263 & 0.1890 & 0.1374 & 0.0852 & 0.3005 \\
\hline & RMS & 0.0019 & 0.0061 & 0.0045 & 0.0035 & 0.0069 \\
\hline \multirow[t]{6}{*}{ van't Hoff } & $K_{a} \times 10^{3}$ & $(737.6 \pm 35.1)$ & $(633.3 \pm 47.9)$ & $(577.4 \pm 63.6)$ & $(484.3 \pm 21.4)$ & $(391.2 \pm 55.7)$ \\
\hline & $\Delta_{\mathrm{ads}} G^{\circ}(\mathrm{kJ} / \mathrm{mol})$ & $-33.55 \pm 8.10$ & $-33.70 \pm 8.14$ & $-33.86 \pm 8.17$ & $-34.02 \pm 8.21$ & $-34.17 \pm 8.25$ \\
\hline & $\Delta_{\mathrm{ads}} H^{\circ}(\mathrm{kJ} / \mathrm{mol})$ & - & - & $-24.23 \pm 2.16$ & - & - \\
\hline & $\Delta_{\mathrm{ads}} S^{\circ}(\mathrm{J} / \mathrm{K} \mathrm{mol})$ & - & - & $31.24 \pm 7.01$ & - & - \\
\hline & $R^{2}$ & - & - & 0.9690 & - & - \\
\hline & $\chi^{2}$ & - & - & $1.42 \times 10^{-4}$ & - & - \\
\hline
\end{tabular}

$n$, the less linear the adsorption isotherm becomes as its behavior deviates further away from the linear (Do, 1998).

Sips (1948) recognized the problem of the continuing, endless increase in adsorption capacity with increasing concentration in the Freundlich equation. Therefore the proposed an equation similar in form to the Freundlich equation, but it has a finite limit when the concentration is sufficiently high as follows $($ Do, 1998):

$q_{e}=Q_{\max } \frac{\left(b C_{e}\right)^{1 / n}}{1+\left(b C_{e}\right)^{1 / n}}$

where $q_{e}(\mathrm{mg} / \mathrm{g})$ is the equilibrium adsorption capacity, $C_{e}(\mathrm{mg} / \mathrm{L})$ is the equilibrium adsorbate concentration in the solution, and $Q_{\max }(\mathrm{mg} / \mathrm{g})$ and $b(\mathrm{~L} / \mathrm{mg})$ are constants related to the maximum adsorption capacity and bonding energy of adsorption/affinity, respectively. The Langmuir-Freundlich (Sips) isotherm resembles the Langmuir isotherm. The difference between the Sips and Langmuir isotherms is the additional parameter $n$ in the Sips equation. If this parameter $n$ is unity, it returns to the Langmuir equation applicable for ideal surfaces. Hence the parameter $n$ can be regarded as the parameter characterizing the system's heterogeneity.

The selection of an isotherm model was based on evaluating the higher determination coefficients $\left(R^{2}\right)$ values together with the smallest difference between the calculated $\left(q_{e, \text { calc }}\right)$ and experimental ( $\left.q_{e, \exp }\right)$ according to root mean square (RMS) error analysis (Nunes et al., 2011) as follows:

$\mathrm{RMS}=\frac{\sqrt{\sum_{i=1}^{N}\left[\left(q_{e, \text { calc }}-q_{e, \exp }\right) / q_{e, \exp }\right]^{2}}}{N}$

where $q_{e, \text { calc }}$ and $q_{e, \text { exp }}$ are the calculated and experimental equilibrium adsorption capacities, respectively, and $N$ is the number of experimental isotherm data points.

The adsorption isotherms obtained at $25,30,35,40$ and $45^{\circ} \mathrm{C}$ with an adsorbent dose of $0.2 \mathrm{~g} / \mathrm{L}$, shaking speed of $150 \mathrm{rpm}$ and pH 7.0 are presented in Fig. 6. Table 4 shows the calculated results for the three isotherm models tested using Microcal Origin 9.1 ${ }^{\mathrm{TM}}$ set to use the Levenberg Marquardt iteration algorithm and weights as statistics (experimental equilibrium data available in Supplementary Table 2). As can be seen in Table 4, the behavior of the isotherms at different temperatures was best described by the Langmuir-Freundlich (Sips) isotherm model, which exhibited the lowest values of RMS and highest values of $R^{2}$. The lower values of $R^{2}$ and the higher values of RMS for the Freundlich model indicated that this model cannot describe the adsorption of $\mathrm{CV}$ onto SMA. The values of RMS and $R^{2}$ for the Langmuir isotherm were relatively close to those in the Sips isotherm, which was expected due to the increase in the parameter $n$ as the temperature increased. The increase in the parameter $n$ means that the system's heterogeneity decreased as the temperature increased, and that the Sips isotherm approached the Langmuir isotherm. From the calculated parameters for the Langmuir isotherm (Table 4), it is possible to note that the maximum monolayer adsorption capacity,

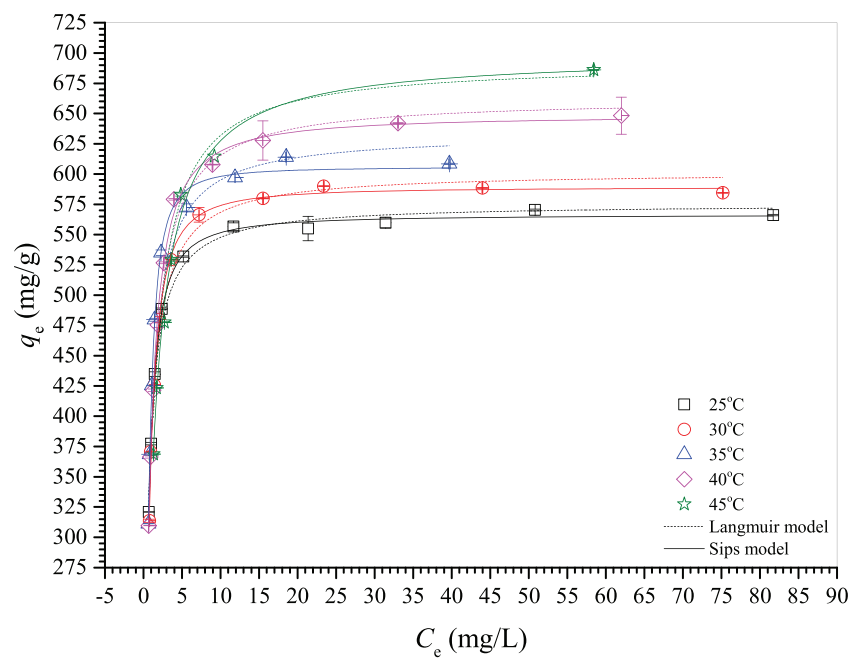

Fig. 6. Langmuir and Sips equilibrium adsorption isotherms for adsorption of $C V$ onto SMA at pH 7, $150 \mathrm{rpm}$ and equilibrium time of $12 \mathrm{~h}$. 

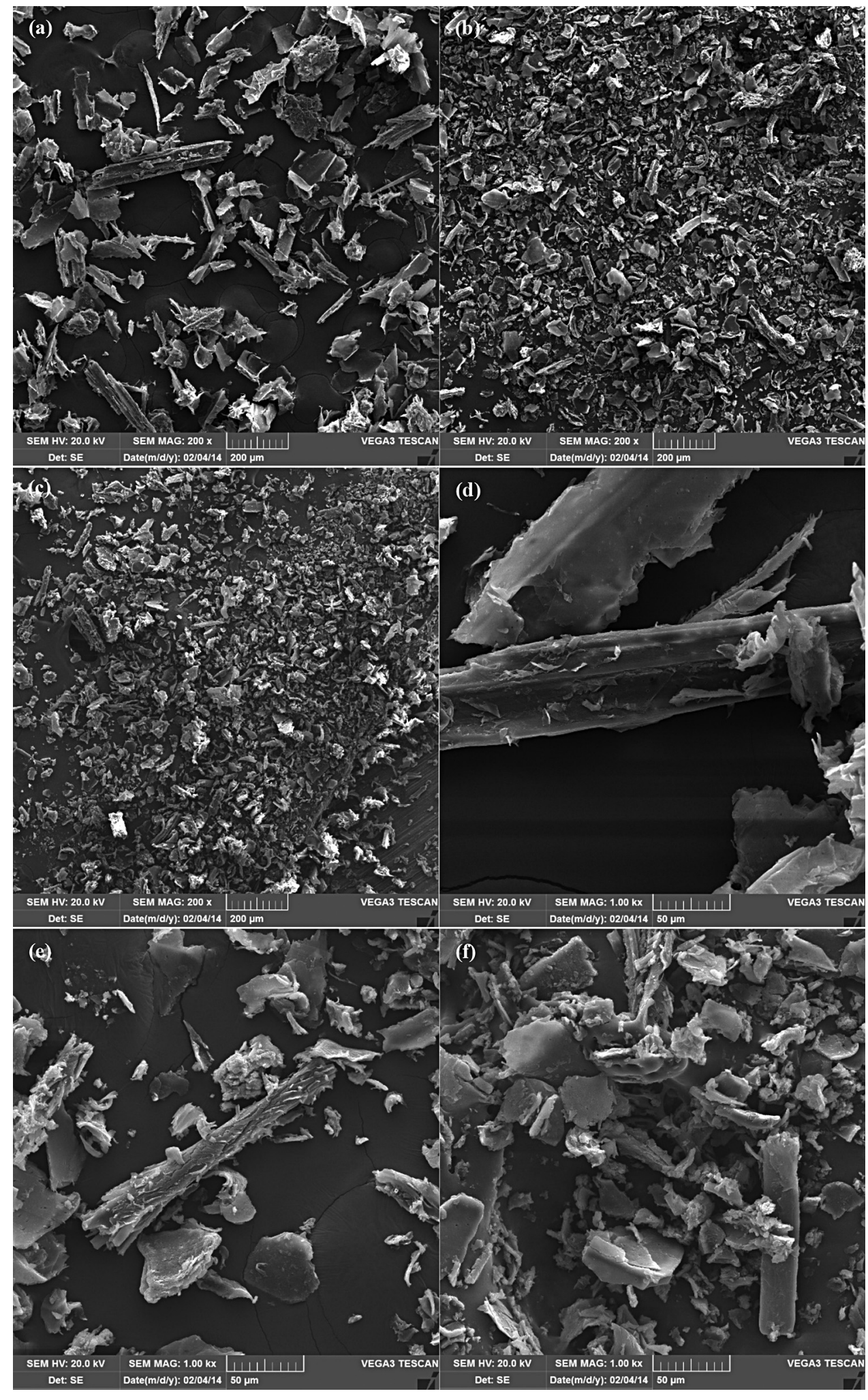

Fig. 7. SEM micrographs of SB (a) and (d) and SMA before (b) and (e) and after adsorption of CV (c) and (f) at 200 and 1000 fold magnification, respectively.

$Q_{\max }$, increased as the temperature increased, raising the value of $Q_{\max }$ from $575.5\left(25^{\circ} \mathrm{C}\right)$ to $692.1 \mathrm{mg} / \mathrm{g}\left(45^{\circ} \mathrm{C}\right)$. This observed behavior for $Q_{\max }$ was contrary to that noticed for the Langmuir constant, $b$, which is related to the affinity of the binding sites for adsorbate molecules. These results indicate that an increase in the temperature decreased the affinity of the adsorbent surface sites for $\mathrm{CV}$ molecules. The shape of the isotherms and the values of the separation factor, $R_{L}$ (Table 4 ), also indicate favorable adsorption with regard to increasing temperature. The value of $n_{\mathrm{COO}}$ - for the SMA adsorbent $(2.65 \mathrm{mmol} / \mathrm{g})$ indicates that, at $25^{\circ} \mathrm{C}$ and $45^{\circ} \mathrm{C}$, the $Q_{\text {max,Langmuir }}: n_{\mathrm{COO}}-$ ratio was 0.532 and 0.640 , respectively. These values indicate that more than one negative charge on the surface of the SMA is being used to adsorb each CV dye molecule. In addition the values of $Q_{\text {max,Langmuir }}: n_{\mathrm{COO}}$ - ratio at $25^{\circ} \mathrm{C}$ and $45^{\circ} \mathrm{C}$ 
were lower than unity. Therefore, it suggests the formation of a monolayer of the CV dye molecules on SMA adsorbent surface.

The thermodynamic parameter, $\Delta_{\mathrm{ads}} G^{\circ}$, is the change in the free energy of the system when one mole of CV dye molecules under infinite dilution in the solution is adsorbed on an infinite area of material. According to thermodynamic law, the free energy of adsorption $\left(\Delta_{\mathrm{ads}} G^{\circ}\right)$ can be calculated as follows:

$\Delta_{\text {ads }} G^{\circ}=-R T \ln K_{a}$

in which $K_{a}$ is the thermodynamic equilibrium constant estimated as recommended by Liu (2009), $T(\mathrm{~K})$ is the absolute temperature and $R(\mathrm{~J} / \mathrm{K} \mathrm{mol})$ is the ideal gas constant $(8.314 \mathrm{~J} / \mathrm{K} \mathrm{mol})$. The classic relationship of $\Delta_{\mathrm{ads}} G^{\circ}$ with the change in the enthalpy $\left(\Delta_{\mathrm{ads}} H^{\circ}\right)$ and change in the entropy $\left(\Delta_{\text {ads }} S^{\circ}\right)$ of adsorption is as follows:

$\Delta_{\text {ads }} G^{\circ}=\Delta_{\text {ads }} H^{\circ}-T \Delta_{\text {ads }} S^{\circ}$

Substituting Eq. (21) into Eq. (22) gives

$\ln K_{a}=-\frac{\Delta H^{\circ} \text { ads }}{R T}+\frac{\Delta S^{\circ} \text { ads }}{R}$

The plot of $\ln K_{\mathrm{a}}$ versus $1 / T$ yielded a straight line from which $\Delta_{\text {ads }} H^{\circ}$ and $\Delta_{\text {ads }} S^{\circ}$ were calculated from the slope and intercept, respectively (Supplementary Figure 3 ). $\Delta_{\text {ads }} G^{\circ}$ values were obtained from Eq. (22) for the different temperatures studied. The calculated results are presented in Table 4. These thermodynamic parameters are useful for a better understanding of the mechanism of the adsorption process. As can be seen in Table 4, the thermodynamic equilibrium constant, $K_{a}$, decreased with temperature similar to the affinity constant of Langmuir. The $\Delta_{\text {ads }} G^{\circ}$ values became more negative as the temperature was increased, indicating that the adsorption process is more spontaneous at higher temperatures. When adsorption of CV occurs with a decrease in the free energy of the system, one can understand why the molecules of CV dye prefer the interface of the SMA to the solution, evaluating the factors that contribute to $\Delta_{\text {ads }} G^{\circ}$, i.e. the contribution of $\Delta_{\text {ads }} H^{\circ}$ and $\Delta_{\text {ads }} S^{\circ}$.

The negative value of $\Delta_{\text {ads }} H^{\circ}(-24.23 \pm 2.16)$ indicates that the adsorption process is exothermic. The negativity of $\Delta_{\text {ads }} H^{\circ}$ means that energy is released from the adsorption at infinite dilution (Do, 1998). The positive value of $\Delta_{\mathrm{ads}} S^{\circ}(31.24 \pm 7.01)$ confirms an increased randomness in the system, including at the solid-solute interface, during the adsorption process (Kaur et al., 2013; Nunes et al., 2011). As the adsorption process occurs, $\Delta_{\text {ads }} G^{\circ}$ must decrease. Since $\Delta_{\text {ads }} H^{\circ}=\Delta_{\text {ads }} G^{\circ}+T \Delta_{\text {ads }} S^{\circ}<0$, the increase in randomness $\left(\Delta_{\mathrm{ads}} S^{\circ}\right)$ must be low, i.e. no remarkable change in entropy can occur during adsorption (Liu, 2009) because of the thermodynamic compensation effect (Do, 1998). This effect justifies the low value of $\Delta_{\text {ads }} S^{\circ}$ found.

The value of $\Delta_{\text {ads }} S^{\circ}$ indicates that CV adsorption on SMA has a small entropic contribution. The $\Delta_{\text {ads }} S^{\circ}$ value also indicates that the entropy of the system increased very little with the adsorption of $\mathrm{CV}$ on the SMA. The adsorption of CV dye molecules on the surface of the SMA caused a decrease in the degree of translational freedom of the CV molecules, resulting in a decrease in the system's entropy. Moreover, water molecules are released through desolvation from the SMA and CV. However, the decrease in system entropy caused by the adsorption of $\mathrm{CV}$ compensates for the increase in system entropy due to the release of water molecules involved in solvating the SMA and CV, so that the net resulting change in system entropy is low.

The standard molar enthalpy of adsorption $\left(\Delta_{\text {ads }} H^{\circ}\right)$ is comprised by several contributions (Haynes et al., 1994; Norde and Lyklema, 1979). For CV adsorption on the SMA surface three subprocesses are ocurring: $(i)$ changes in the state of hydration of the surface of the adsorbent and dye molecules ( $\left.\Delta_{\text {ads }} H_{\text {hyd }}\right)$, (ii) the variation in the dye-adsorbent interaction energy ( $\left.\Delta_{\text {int }} H_{\text {dye-SMA }}\right)$, (iii) water-water interactions $\left(\Delta_{\mathrm{ads}} \mathrm{H}_{\mathrm{H}_{2} \mathrm{O}-\mathrm{H}_{2} \mathrm{O}}\right) \cdot \Delta_{\mathrm{ads}} \mathrm{H}^{\circ}$ can be calculated by adding all these contributions according to Eq. (24).

$\Delta_{\text {ads }} H^{\circ}=\Delta_{\text {ads }} H_{\text {hyd }}+\Delta_{\text {int }} H_{\text {dye-SMA }}+\Delta_{\text {ads }} H_{\mathrm{H}_{2} \mathrm{O}-\mathrm{H}_{2} \mathrm{O}}$

The $\Delta_{\text {ads }} H^{\circ}$ value shows that the adsorption of CV is enthalpy favored, i.e. it occurs with overall reduction of the enthalpy of the system. Thus, in order to understand the exothermic enthalpic contribution to the adsorption process we need to evaluate the contribution of each sub-process.

The first input, $\Delta_{\text {ads }} H_{\text {hyd }}$, refers to the desolvation of the dye molecules and the surface of the SMA. Energy is necessary to break SMA-water and dye-water interactions, contributing to a endothermic $\Delta_{\text {ads }} H^{\circ}$. The second contribution, $\Delta_{\text {int }} H_{\text {dye-SMA }}$, refers to SMA-dye interactions. These interactions include hydrophobic intractions, hydrogen bonding, ion pairing, ion dipole, dipole-dipole, induced dipole dipole, and van der Walls, contributing to an exothermic $\Delta_{\text {ads }} H^{\circ}$. The third input, $\Delta_{\text {ads }} H_{\mathrm{H}_{2} \mathrm{O}-\mathrm{H}_{2} \mathrm{O}}$, is associated with hydrogen bonding between water molecules released during desolvation, contributing to an exothermic $\Delta_{\text {ads }} H^{\circ}$.

Basically, according to Liu (2009), the change in enthalpy involved during physical adsorption is in the range of $2.1-20.9 \mathrm{~kJ} / \mathrm{mol}$, whereas for chemisorption it falls in the range of $80-200 \mathrm{~kJ} / \mathrm{mol}$. Hence, the value of $\Delta_{\mathrm{ads}} H^{\circ}(-24.23 \mathrm{~kJ} / \mathrm{mol})$ for $\mathrm{CV}$ adsorption by SMA suggests a physisorption mechanism controlling the adsorption process, which corroborates with the analysis of the adsorption mechanism from the value of the activation energy obtained from kinetic studies.

It is essential to emphasize that the adsorption mechanism of the CV dye molecules on SMA adsorbent cannot be directly concluded from the pseudo-second-order kinetic model, the Langmuir and Sips isotherm models. However, it can be concluded that the adsorption isotherm of CV dye shows the Langmuir behavior, which indicates the formation of a monolayer and chemisorption. In addition, the Sips isotherm model, a combination of the Langmuir and Freundlich models, indicates a decreasing in the heterogeneous character of the system as the temperature increased. Although the Langmuir model failed to a certain degree to represent fully the adsorption behavior of the CV dye molecules on SMA adsorbent, the use of the estimated Langmuir constants to determine the thermodynamic parameters of adsorption using the van't Hoff equation is essential. Therefore, as the adsorption system does not obey all the assumptions of the abovementioned models the adsorption mechanism was concluded from thermodynamic parameters and activation energy as physisorption. Similar analysis of the adsorption models and thermodynamic data was also reported by Al-Ghouti et al. (2003).

\subsubsection{Comparison with literature data for CV adsorption}

Table 5 shows various materials used to remove CV from aqueous solutions reported in the literature for comparison purposes. The comparison shows that SMA has a greater maximum adsorption capacity $\left(Q_{\max }\right)$ for $C V$ than those adsorbent materials reported in Table 5. In addition, the SMA adsorbent was prepared using a solvent-free method, which diminishes the preparation costs since it is not necessary to dispose of toxic organic solvents. In preparing the SMA, unreacted Meldrum's acid and acetone can be recovered by vacuum filtration and distillation, respectively. Furthermore, decomposed Meldrum's acid can be regenerated through a condensation reaction between malonic acid and acetone in the presence of sulfuric acid as a catalyst (Nesterova et al., 1994). This regeneration of Meldrum's acid can contribute to reducing the preparation costs of SMA. 
Table 5

Comparison of $Q_{\max }, E_{a}, \Delta_{\text {ads }} G^{\circ}, \Delta_{\text {ads }} H^{\circ}$ and $\Delta_{\text {ads }} S^{\circ}$ for removal of CV by SMA with various adsorbent materials.

\begin{tabular}{|c|c|c|c|c|c|c|}
\hline Adsorbent material & $Q_{\max }(\mathrm{mg} / \mathrm{g})^{\mathrm{a}}$ & $E_{\mathrm{a}}(\mathrm{kJ} / \mathrm{mol})$ & $\Delta_{\mathrm{ads}} G^{\circ}(\mathrm{kJ} / \mathrm{mol})$ & $\Delta_{\text {ads }} H^{\circ}(\mathrm{kJ} / \mathrm{mol})$ & $\Delta_{\mathrm{ads}} S^{\circ}(\mathrm{J} / \mathrm{K} . \mathrm{mol})$ & Reference \\
\hline $\begin{array}{l}\text { Sugarcane bagasse } \\
\text { modified with } \\
\text { Meldrum's acid }\end{array}$ & 692.1 & -14.14 & $-33.70\left(30^{\circ} \mathrm{C}\right)$ & -24.23 & 31.24 & This work \\
\hline $\begin{array}{r}\text { Citric acid esterifying } \\
\text { wheat straw (EWS) }\end{array}$ & 227.27 & - & $-19.81\left(30^{\circ} \mathrm{C}\right)$ & 32.62 & 172.95 & Gong et al. (2008) \\
\hline $\begin{array}{l}\text { Treated ginger waste } \\
\text { (TGW) }\end{array}$ & 277.77 & - & $-3.40\left(30^{\circ} \mathrm{C}\right)$ & 64.43 & 0.225 & Kumar and Ahmad (2011) \\
\hline $\begin{array}{l}\text { Coniferous pinus bark } \\
\text { powder (CPBP) }\end{array}$ & 32.78 & - & $-6.42\left(30^{\circ} \mathrm{C}\right)$ & 20.24 & 80.0 & Ahmad (2009) \\
\hline Jackfruit leaf powder (JLP) & 43.40 & 45.98 & $-21.46\left(30^{\circ} \mathrm{C}\right)$ & -110.50 & -292.38 & Saha et al. (2012) \\
\hline $\begin{array}{l}\text { NaOH-modified rice husk } \\
(\mathrm{NMRH})\end{array}$ & 41.5 & 50.51 & $-13.93\left(30^{\circ} \mathrm{C}\right)$ & -80.43 & -220.0 & Chakraborty et al. (2011) \\
\hline $\begin{array}{l}\text { Phosphoric acid activated } \\
\text { carbon (PAAC) }\end{array}$ & 60.42 & $58.69^{\mathrm{b}}$ & $-79.11\left(33^{\circ} \mathrm{C}\right)$ & 71.49 & 258.76 & Senthilkumaar et al. (2006) \\
\hline $\begin{array}{l}\text { Sulfuric acid activated } \\
\text { carbon (SAAC) }\end{array}$ & 85.84 & $-5.60^{b}$ & $-32.94\left(33^{\circ} \mathrm{C}\right)$ & 73.38 & 107.90 & Senthilkumaar et al. (2006) \\
\hline Eichhornia charcoal (EC) & 58.13 & 31.82 & $-29.29\left(30^{\circ} \mathrm{C}\right)$ & 9.16 & 127.0 & Kaur et al. (2013) \\
\hline Bottom ash (BA) & 4.0 & 39.43 & $-33.0\left(30^{\circ} \mathrm{C}\right)$ & 40.95 & 36.53 & Mittal et al. (2010) \\
\hline De-oil soya (DOS) & 5.79 & 12.75 & $32.8\left(30^{\circ} \mathrm{C}\right)$ & 59.02 & 36.66 & Mittal et al. (2010) \\
\hline
\end{tabular}

a Maximum adsorption capacities calculated from Langmuir model.

b Determined from diffusion equation using Reichenberg's plot.

\subsection{Desorption and reuse of the SMA adsorbent}

The adsorption of CV onto SMA was performed using $20.0 \mathrm{mg}$ of SMA, a $180 \mathrm{mg} / \mathrm{L} \mathrm{CV}$ solution, $\mathrm{pH} 7$ and $12 \mathrm{~h}$ of shaking at $25^{\circ} \mathrm{C}$. The value of $Q_{\max }$ calculated using Eq. (4) was $423.8 \mathrm{mg} / \mathrm{g}$. The desorption of CV was carried out by a batch process at $25^{\circ} \mathrm{C}$ using $100.0 \mathrm{~mL}$ aqueous solutions of $1.0 \mathrm{~mol} / \mathrm{L} \mathrm{CH}_{3} \mathrm{COOH}$ or $0.01 \mathrm{~mol} / \mathrm{L} \mathrm{HCl}$ for $6 \mathrm{~h}$, which were the best conditions established from the optimization studies of desorption as a function of concentration of $\mathrm{CH}_{3} \mathrm{COOH}$ or $\mathrm{HCl}$ and time. The percentages of $\mathrm{CV}$ desorption for $1.0 \mathrm{~mol} / \mathrm{L}$ $\mathrm{CH}_{3} \mathrm{COOH}$ and $0.01 \mathrm{~mol} / \mathrm{L} \mathrm{HCl}$ solutions after $6 \mathrm{~h}$ of shaking were found to be $61.6 \pm 4.6 \%$ and $57.9 \pm 2.6 \%$, respectively.

As CV dye was not totally desorbed from the SMA adsorbent with either desorption solution, the reusability of the SMA was evaluated in order to verify whether the adsorption capacity was affected by the desorption process through degradation of the adsorbent in the acidic medium. The re-adsorption was performed using the same experimental conditions previously described. The re-adsorption efficiencies for SMA loaded with CV desorbed with either $1.0 \mathrm{~mol} / \mathrm{L}$ $\mathrm{CH}_{3} \mathrm{COOH}$ or $0.01 \mathrm{~mol} / \mathrm{L} \mathrm{HCl}$ were calculated using Eq. (6) and found to be 82.2 and $100 \%$, respectively. These results suggest that, even though desorption of CV from the SMA by a batch process is not complete, the SMA adsorbent can still be reused without loss of adsorption capacity when $0.01 \mathrm{~mol} / \mathrm{L} \mathrm{HCl}$ is used as the desorption solution. Ahmad (2009) reported a desorption efficiency of CV from coniferous pinus bark powder (CPBP) using a batch process with $1 \mathrm{~mol} / \mathrm{L} \mathrm{CH}_{3} \mathrm{COOH}$ of $88 \%$. The desorption efficiency found in the present study suggests that CV dye molecules are strongly bound to adsorption sites on the surface of the SMA even when the carboxylate groups are protonated $(\mathrm{pH} 2)$, indicating that electrostatic interactions are not the only forces responsible for adsorption of $\mathrm{CV}$ onto SMA. It also suggests that under acidic $\mathrm{pH}$, interactions such as hydrogen bonding between deprotonated amine groups $\left(-\mathrm{N}\left(\mathrm{CH}_{3}\right)_{2}\right)$ in the $\mathrm{CV}$ and hydroxyl groups from the carboxylic acid groups $(-\mathrm{COOH})$ in the SMA, along with van der Waals forces, may be responsible for keeping CV dye molecules bound to the SMA's surface (Kumar and Ahmad, 2011).

\section{Conclusions}

Sugarcane bagasse was successfully modified with Meldrum's acid using a solvent-free system. The adsorbent material (SMA) was very efficient in removing crystal violet (CV) from aqueous solutions. The adsorption of CV onto SMA reached equilibrium after $12 \mathrm{~h}$ and was favored at $\mathrm{pH}$ 7.0. Adsorption kinetics followed the pseudo-second-order model and the rate constants increased with increasing temperature. The intraparticle diffusion model revealed that adsorption occurs in two steps. The Arrhenius activation energy $(14.14 \mathrm{~kJ} / \mathrm{mol})$ suggests that physical adsorption is the major mechanism controlling the adsorption of CV onto SMA. The equilibrium data was modeled using three isotherm models and the experimental data fitted very well to the Langmuir and Sips models. Both models revealed that maximum adsorption capacity increased as the temperature increased, reaching $692.1 \mathrm{mg} / \mathrm{g}$ at $45^{\circ} \mathrm{C}$ according to the Langmuir model. SMA has a higher $Q_{\max }$ for $\mathrm{CV}$ than other adsorbent materials reported in the literature. The value of the enthalpy change indicates that the adsorption process is exothermic. Desorption of $\mathrm{CV}$ attained values close to $60 \%$ using $\mathrm{CH}_{3} \mathrm{COOH}$ and $\mathrm{HCl}$ as desorption solutions. Studies of re-adsorption proved that SMA can be reused without loss of its adsorption capacity.

\section{Acknowledgments}

The authors are grateful to Universidade Federal de Ouro Preto (UFOP) (for Filipe S. Teodoro's undergraduate PIPES scholarship) and Fundação de Amparo à Pesquisa do Estado de Minas Gerais (FAPEMIG) for funding this research (FAPEMIG grant numbers CEX APQ-00149/12 and CEX APQ-01168/12). The authors are also grateful to Coordenação de Aperfeiçoamento de Pessoal de Nível Superior (CAPES) (for Bruno C. S. Ferreira's Ph.D. scholarship) and Conselho Nacional de Desenvolvimento Científico (CNPq) (for Rossimiriam P. Freitas and Laurent F. Gil grants), Laboratório de microscopia eletrônica, microanálises e caracterização de materiais (NanoLab/FINEP - Redemat, Escola de Minas, UFOP) and B.S. Ney P. Sampaio for SEM analyses.

\section{Appendix A. Supplementary data}

Supplementary data associated with this article can be found, in the online version, at http://dx.doi.org/10.1016/j.indcrop.2014. 10.020 . 


\section{References}

Abdolali, A., Guo, W.S., Ngo, H.H., Chen, S.S., Nguyen, N.C., Tung, K.L., 2014. Typical lignocellulosic wastes and by-products for biosorption process in water and wastewater treatment: a critical review. Bioresour. Technol. 160, 57-66.

Ahmad, R., 2009. Studies on adsorption of crystal violet dye from aqueous solution onto coniferous pinus bark powder (CPBP). J. Hazard. Mater. 171, 767-773.

Al-Ghouti, M.A., Khraisheh, M.A.M., Allen, S.J., Ahmad, M.N., 2003. The removal of dyes from textile wastewater: a study of the physical characteristics and adsorption mechanisms of diatomaceous earth. J. Environ. Manage. 69, 229-238.

Ali, H., 2010. Biodegradation of synthetic dyes-a review. Water Air Soil Pollut. 213, 251-273.

Anirudhan, T.S., Radhakrishnan, P.G., 2008. Thermodynamics and kinetics of adsorption of $\mathrm{Cu}$ (II) from aqueous solutions onto a new cation exchanger derived from tamarind fruit shell. J. Chem. Thermodyn. 40, 702-709.

Bigi, F., Carloni, S., Ferrari, L., Maggi, R., Mazzacani, A., Sartori, G., 2001. Clean synthesis in water. Part 2: Uncatalysed condensation reaction of Meldrum's acid and aldehydes. Tetrahedron Lett. 42, 5203-5205.

Brosillon, S., Djelal, H., Merienne, N., Amrane, A., 2008. Innovative integrated process for the treatment of azo dyes: coupling of photocatalysis and biological treatment. Desalination 222, 331-339.

Chakraborty, S., Chowdhury, S., Das Saha, P., 2011. Adsorption of Crystal Violet from aqueous solution onto $\mathrm{NaOH}$-modified rice husk. Carbohydr. Polym. 86, 1533-1541.

Cotoruelo, L.M., Marqués, M.D., Díaz, F.J., Rodríguez-Mirasol, J., Rodríguez, J.J., Cordero, T., 2012. Lignin-based activated carbons as adsorbents for crystal violet removal from aqueous solutions. Environ. Prog. Sustain. Energy 31, 386-396.

Do, D., 1998. Adsorption Analysis: Equilibria and Kinetics. Imperial College Press, London.

Ehlert, G.J., Lin, Y., Sodano, H.A., 2011. Carboxyl functionalization of carbon fibers through a grafting reaction that preserves fiber tensile strength. Carbon 49, 4246-4255.

Fayoumi, L.M.A., Ezzedine, M.A., Akel, H.H., El Jamal, M.M., 2012. Kinetic study of the degradation of crystal violet by $\mathrm{K}_{2} \mathrm{~S}_{2} \mathrm{O}_{8}$. Comparison with Malachite Green. Portugaliae Electrochim. Acta 30, 121-133.

Freundlich, H.M.F., 1906. Over the adsorption in solution. Z. Phys. Chem-Stoch. Ve. $57,385-470$

Gong, R.M., Zhu, S.X., Zhang, D.M., Chen, J., Ni, S.J., Guan, R., 2008. Adsorption behavior of cationic dyes on citric acid esterifying wheat straw: kinetic and thermodynamic profile. Desalination 230, 220-228.

Gupta, V.K., Ali, I., Saleh, T.A., Nayak, A., Agarwal, S., 2012. Chemical treatment technologies for waste-water recycling - an overview. RSC Adv. 2, 6380-6388.

Gupta, V.K., Suhas, 2009. Application of low-cost adsorbents for dye removal - a review. J. Environ. Manage. 90, 2313-2342.

Gurgel, L.V.A., de Freitas, R.P., Gil, L.F., 2008. Adsorption of $\mathrm{Cu}(\mathrm{II}), \mathrm{Cd}(\mathrm{II})$, and $\mathrm{Pb}(\mathrm{II})$ from aqueous single metal solutions by sugarcane bagasse and mercerized sugarcane bagasse chemically modified with succinic anhydride. Carbohydr. Polym. 74, 922-929.

Gusmao, K.A.G., Gurgel, L.V.A., Melo, T.M.S., Gil, L.F., 2012. Application of succinylated sugarcane bagasse as adsorbent to remove methylene blue and gentian violet from aqueous solutions - kinetic and equilibrium studies. Dyes Pigments 92, 967-974.

Haynes, C.A., Sliwinsky, E., Norde, W., 1994. Structural and electrostatic properties of globular-proteins at a polystyrene water interface. J. Colloid Interface Sci. 164, 394-409.

Ho, Y.S., McKay, G., 1998. Kinetic models for the sorption of dye from aqueous solution by wood. Process Saf. Environ. Prot. 76, 183-191.

Kalidhasan, S., Gupta, P.A., Cholleti, V.R., Santhana Krishna Kumar, A., Rajesh, V., Rajesh, N., 2012. Microwave assisted solvent free green preparation and physicochemical characterization of surfactant-anchored cellulose and its relevance toward the effective adsorption of chromium. J. Colloid Interface Sci. 372, 88-98.

Karnitz, O., Gurgel, L.V.A., de Freitas, R.P., Gil, L.F., 2009. Adsorption of Cu(II), Cd(II), and $\mathrm{Pb}(\mathrm{II})$ from aqueous single metal solutions by mercerized cellulose and mercerized sugarcane bagasse chemically modified with EDTA dianhydride (EDTAD). Carbohydr. Polym. 77, 643-650.

Kaur, S., Rani, S., Mahajan, R.K., 2013. Adsorptive removal of dye crystal violet onto low-cost carbon produced from Eichhornia plant: kinetic, equilibrium, and thermodynamic studies. Desalin. Water Treat., 1-14.

Kumar, R., Ahmad, R., 2011. Biosorption of hazardous crystal violet dye from aqueous solution onto treated ginger waste (TGW). Desalination 265, 112-118.

Lagergren, S.Y., 1898. Zur Theorie der sogenannten Adsorption gelöster Stoffe, Kungliga Svenska Vetenskapsakademiens. Handlingar 24, 1-39.

Langmuir, I., 1918. The adsorption of gases on plane surfaces of glass, mica and platinum. J. Am. Chem. Soc. 40, 1361-1403.

Leibfarth, F.A., Kang, M., Ham, M., Kim, J., Campos, L.M., Gupta, N., Moon, B., Hawker, C.J., 2010. A facile route to ketene-functionalized polymers for general materials applications. Nat. Chem. 2, 207-212.

Liang, C.-Z., Sun, S.-P., Li, F.-Y., Ong, Y.-K., Chung, T.-S., 2014. Treatment of highly concentrated wastewater containing multiple synthetic dyes by a combined process of coagulation/flocculation and nanofiltration. J. Membr. Sci. 469, 306-315.

Liu, C.F., Sun, R.C., Qin, M.H., Zhang, A.P., Ren, J.L., Ye, J., Luo, W., Cao, Z.N., 2008. Succinoylation of sugarcane bagasse under ultrasound irradiation. Bioresour. Technol. 99, 1465-1473.
Liu, Y., 2009. Is the free energy change of adsorption correctly calculated. J. Chem. Eng. Data 54, 1981-1985.

Liu, Y., Lin, J., Chen, M., Song, L., 2013. Investigation on the interaction of the toxicant, gentian violet, with bovine hemoglobin. Food Chem. Toxicol. 58, 264-272.

Ma, S., Xue, X.-L., Yu, S.-J., Wang, Z.-H., 2012. High-intensity ultrasound irradiated modification of sugarcane bagasse cellulose in an ionic liquid. Ind. Crop Prod. $35,135-139$

Matouq, M., Al-Anber, Z., Susumu, N., Tagawa, T., Karapanagioti, H., 2014. The kinetic of dyes degradation resulted from food industry in wastewater using high frequency of ultrasound. Sep. Purif. Technol. 135, 42-47.

Melo, J.C.P., Silva Filho, E.C., Santana, S.A.A., Airoldi, C., 2011. Synthesized cellulose/succinic anhydride as an ion exchanger. Calorimetry of divalent cations in aqueous suspension. Thermochim. Acta 524, 29-34.

Mittal, A., Mittal, J., Malviya, A., Kaur, D., Gupta, V.K., 2010. Adsorption of hazardous dye crystal violet from wastewater by waste materials. J. Colloid Interface Sci. 343, 463-473.

Nada, A.-A.M.A., Hassan, M.L., 2006. Ion exchange properties of carboxylated bagasse. J. Appl. Polym. Sci. 102, 1399-1404.

Nesterova, I.N., Shanazarov, A.K., Poznyak, A.M., Lakoza, M.I., Shemeryankin, B.V. Granik, V.G., 1994. Improved method of synthesizing 2,2-dimethyl-4,6-dioxo1,3-dioxane (Meldrum's acid). Pharm. Chem. J. 28, 583-585.

Noh, J.S., Schwarz, J.A., 1990. Effect of $\mathrm{HNO}_{3}$ treatment on the surface acidity of activated carbons. Carbon 28, 675-682.

Norde, W., Lyklema, J., 1979. Thermodynamics of protein adsorption - theory with special reference to the adsorption of human-plasma albumin and bovine pancreas ribonuclease at polystyrene surfaces. J. Colloid Interface Sci. 71, 350-366

Nunes, D.L., Franca, A.S., Oliveira, L.S., 2011. Use of Raphanus sativus L. press cake, a solid residue from biodiesel processing, in the production of adsorbents by microwave activation. Environ. Technol. 32, 1073-1083.

Pang, Y.L., Abdullah, A.Z., 2013. Current status of textile industry wastewater management and research progress in Malaysia: a review. Clean - Soil Air Water 41 $751-764$.

Pippo, W., Luengo, C., 2013. Sugarcane energy use: accounting of feedstock energy considering current agro-industrial trends and their feasibility. Int. J. Energy Environ. Eng. 4, 1-13.

Ryu, Y., Scott, A.I., 2003. Self-condensation of activated malonic acid half esters: a model for the decarboxylative Claisen condensation in polyketide biosynthesis. Tetrahedron Lett. 44, 7499-7502.

Saba, B., Khalid, A., Nazir, A., Kanwal, H., Mahmood, T., 2013. Reactive black-5 azo dye treatment in suspended and attach growth sequencing batch bioreactor using different co-substrates. Int. Biodeterior. Biodegrad. 85, 556-562.

Saeed, A., Sharif, M., Iqbal, M., 2010. Application potential of grapefruit peel as dye sorbent: kinetics, equilibrium and mechanism of crystal violet adsorption. J. Hazard. Mater. 179, 564-572.

Saha, P.D., Chakraborty, S., Chowdhury, S., 2012. Batch and continuous (fixed-bed column) biosorption of crystal violet by Artocarpus heterophyllus (jackfruit) leaf powder. Colloids Surf. B: Biointerfaces 92, 262-270.

Sahoo, C., Gupta, A.K., Pal, A., 2005. Photocatalytic degradation of crystal violet (C.I. basic violet 3 ) on silver ion doped $\mathrm{TiO}_{2}$. Dyes Pigments 66, 189-196.

Saquib, M., Muneer, M., 2003. $\mathrm{TiO}_{2}$-mediated photocatalytic degradation of a triphenylmethane dye (gentian violet), in aqueous suspensions. Dyes Pigments 56 37-49.

Senthilkumaar, S., Kalaamani, P., Subburaam, C.V., 2006. Liquid phase adsorption of Crystal violet onto activated carbons derived from male flowers of coconut tree. J. Hazard. Mater. 136, 800-808.

Shaikh, H.M., Pandare, K.V., Nair, G., Varma, A.J., 2009. Utilization of sugarcane bagasse cellulose for producing cellulose acetates: novel use of residual hemicellulose as plasticizer. Carbohydr. Polym. 76, 23-29.

Sips, R., 1948. On the structure of a catalyst surface. J. Chem. Phys. 16, 490-495.

Soliman, E.M., Ahmed, S.A., Fadl, A.A., 2011. Removal of calcium ions from aqueous solutions by sugar cane bagasse modified with carboxylic acids using microwave-assisted solvent-free synthesis. Desalination 278, 18-25.

Thompson Jr., H.C., Rushing, L.G., Gehring, T., Lochmann, R., 1999. Persistence of gentian violet and leucogentian violet in channel catfish (Ictalurus punctatus) muscle after water-borne exposure. J. Chromatogr. B: Biomed. Sci. Appl. 723, 287-291.

Varhegyi, G., Antal, M.J., Szekely, T., Szabo, P., 1989. Kinetics of the thermal decomposition of cellulose, hemicellulose, and sugarcane bagasse. Energy Fuels 3 329-335.

Vieira, A.P., Santana, S.A.A., Bezerra, C.W.B., Silva, H.A.S., de Melo, J.C.P., da Silva Filho, E.C., Airoldi, C., 2010. Copper sorption from aqueous solutions and sugar cane spirits by chemically modified babassu coconut (Orbignya speciosa) mesocarp. Chem. Eng. J. 161, 99-105.

Wang, L., 2012. Application of activated carbon derived from 'waste' bamboo culms for the adsorption of azo disperse dye: kinetic, equilibrium and thermodynamic studies. J. Environ. Manage. 102, 79-87.

Weber, M.J., Morris, J.C., 1963. Kinetic of adsorption on carbon from solution. J. Sanit Eng. Div. ASCE 89, 31-60.

Zhang, W., Li, C., Liang, M., Geng, Y., Lu, C., 2010. Preparation of carboxylatefunctionalized cellulose via solvent-free mechanochemistry and its characterization as a biosorbent for removal of $\mathrm{Pb}^{2+}$ from aqueous solution. J. Hazard Mater. 181, 468-473. 